\title{
Challenges and advances in quantum dot fluorescent probes to detect reactive oxygen and nitrogen species: A review
}

\author{
Oluwasesan Adegoke and Patricia B.C. Forbes
}

Department of Chemistry, Faculty of Natural and Agricultural Sciences, University of Pretoria, Lynnwood Road, Pretoria 0002, South Africa

\begin{abstract}
The pathological and physiological effects of reactive oxygen and nitrogen species (ROS/RNS) have instigated increasing awareness in the scientific field with respect to the development of suitable probes for their detection. Among the various probes developed to date, semiconductor quantum dots (QDs) fluorescent probes have attracted significant attention. The unfavourable properties of ROS/RNS with respect to their detection, such as their short lifetimes and the competitive presence of various endogenous reactive species capable of interfering with the probe in biological matrices, have hindered the effective performance of most probes as well as complicating the design of suitable probes. The development of novel QD fluorescent probes capable of circumventing these problems is thus of scientific interest. In this review, we highlight the challenges faced, pros and cons and published developments to date, with respect to QD fluorescent probes for ROS/RNS such as $\mathrm{H}_{2} \mathrm{O}_{2}, \mathrm{O}_{2} \bullet-, \cdot \mathrm{OH}, \mathrm{HOCl}, \mathrm{NO}$ and ONOO-
\end{abstract}

Keywords: Quantum dots, fluorescence, reactive oxygen species, reactive nitrogen species, sensing

*Corresponding author: +27 613185846

Email address: adegoke.sesan@mailbox.co.za (O. Adegoke), patricia.forbes@up.ac.za (P.B.C. Forbes) 







\section{Introduction}

Oxygen and oxygenated species play critical roles as metabolites in aerobic systems. Despite oxygen being a vital component of life, oxygenated species can impair or destroy the proper functioning of living tissues [1,2]. Reactive oxygen species (ROS) are a combination of molecules that are produced through the partial reduction of molecular oxygen $\left(\mathrm{O}_{2}\right)[3,4]$. Common examples of these species are hydrogen peroxide $\left(\mathrm{H}_{2} \mathrm{O}_{2}\right)$, superoxide radical $\left(\mathrm{O}_{2}^{\bullet-}\right)$, hydroxyl radical $\left(\bullet^{\bullet} \mathrm{OH}\right)$ and hypochlorous acid $(\mathrm{HOCl})$. Despite the body's defence system to generate cell antioxidants against pathological and physiological processes, the overproduction of ROS have played a key role in the development of age-dependent diseases such as neurodegenerative disorders, cancer, arthritis, arteriosclerosis, oxidative stress, and others [5-7].

Another class of chemically reactive species which are specifically involved in cell signalling through a variety of pathological and physiological processes are known as reactive nitrogen species (RNS) [8,9]. Common examples of these species are nitric oxide (NO) and peroxynitrite anion (ONOO-). Various reviews highlighting the chemical and biological functions of ROS/RNS have been published [10-13].

One of the major obstacles confronting researchers who are engaged in developing real-time fluorescent probes for ROS/RNS in live cells is the difficulty in determining the specificity of which species is/are produced at a particular quantity and at a given time [14]. In addition, there are also several challenges associated with the detection of ROS/RNS which will be covered later in this review. Conventional techniques such as mass spectrometry, high performance liquid chromatography and electron paramagnetic resonance spectroscopy (EPR) are among various 
analytical tools that can be exploited to detect specific ROS/RNS produced either from the oxidation of DNA, proteins, other biomolecules [15-18] or from exogenous probes [19]. In some cases, success in the development of probes for species like ONOO-, $\mathrm{HOCl}$ and $\mathrm{O}_{2}{ }^{\bullet-}$ using the above-mentioned techniques have been documented [20-23]. However, the breakthroughs have been short-lived due to the inability of these methods to offer real-time monitoring, hence necessitating a strong push for the development of fluorescent probes. Presently, a variety of synthetic fluorescent probes such as encoded fluorescent proteins, organic fluorophore dyes, small molecule probes and nanoparticle-based fluorescent probes have been developed for ROS/RNS both in vivo and in vitro owing to their simple manipulation and high sensitivities. Generally, various review articles have highlighted the use of fluorescent probes to detect ROS/RNS in aqueous physiological solutions and cellular media [14,24-29]. However, this review focus specifically on the detection of common ROS/RNS such as $\mathrm{H}_{2} \mathrm{O}_{2}, \mathrm{O}_{2}{ }^{\bullet-}, \cdot \mathrm{OH}, \mathrm{HOCl}, \mathrm{NO}$ and $\mathrm{ONOO}^{-}$using nanoparticle-based fluorescent probes involving semiconductor nanocrystal quantum dots (QDs).

Since their discovery in the early 1980s [30-35], QDs have attracted global research attention in several facets of science and technology. QDs nanocrystals whose dimensions are smaller than the size of the material's exciton Bohr radius are known to exhibit a phenomenon known as quantum confinement, defined by the quantization of energy levels to discrete values and by an increasing bandgap [36]. The main properties of QDs which makes them unique amongst other types of fluorescent fluorophores is their strong resistance to photobleaching, high surface-to- 
volume ratio, bright fluorescence, size and shape-dependent fluorescence properties, large Stokes shifts and narrow emission bands $[37,38]$. The objective of this review is to discuss the various fluorescent probes that have been developed to date using QDs composed of group II-VI, IV-VI and III-V semiconductor nanocrystals.

A common pitfall among some published data on the detection of ROS/RNS using various organic fluorescent probes is the unclear reaction mechanism and lack of specificity. This has inspired us to provide an overview of what data has been obtained for different QDs-based fluorescent probes, what information it offers to us and what degree of experimental interpretation has been justified. Generally speaking, the ability of QDs-based fluorescent probes to provide valuable information for the detection of ROS/RNS is still very limited, but we summarize recent advances, what milestones have been achieved to date with regards to mechanistic understanding, and also challenges faced in the emerging field of QD sensor technology for ROS/RNS.

\section{General considerations for the detection of ROS/RNS}

ROS/RNS have long been classified and detected by several fluorophore probes [3957], but due to the complex cellular environment where different e.g. ROS/RNS are present in varying competitive quantities and also due to their fast decomposition rates, it is essential that special approaches are employed to detect the ROS/RNS of interest. Generally speaking, for a QD sensor designed to detect a subset of/or accessible ROS/RNS content of a cell, it is important that a minimal perturbation of the cell is achieved, a process which implies that there should be no competitive 
exchange between the sensor and the endogenously produced species. If this is the case, properties such as the concentration of the sensor within the cell, affinity of the sensor and the nature of the ROS/RNS of interest should be considered in appropriate terms. It is noteworthy that when contemplating the use of any QDbased probe, it is vital to justify what information is required and the possibility of whether it can be obtained with the experimental design or chosen probe. For ROS/RNS detection in buffer solutions, the following parameters are needed and must be demonstrated by appropriate characterization techniques and choice of experimental conditions:

A. Since some ROS/RNS exhibit short lifetimes in physiological $\mathrm{pH}$ solutions, evidence of real-time monitoring at this $\mathrm{pH}$ must be demonstrated.

B. Since some ROS/RNS are known to decompose to other intermediate products at a very fast rate, evidence to show that the decomposition products of ROS/RNS are not being detected but rather the specific ROS/RNS must be shown.

C. Evidence of appropriate techniques to characterize the production and stability of ROS/RNS in aqueous solution must be proven.

For live cell detection, the following parameters may be considered important:

1. Analytical quantitation of how much of the ROS/RNS is produced.

2. Evidence of identification of the site of production.

3. Evidence to show that the cellular redox state may have been perturbed.

4. Specific detection of the ROS/RNS. 


\section{General considerations for a QDs fluorescent sensor}

Presently, there are numerous comprehensive reviews that have focused broadly on the chemistry of group II-VI, IV-VI and III-V QDs, such as their design, synthesis, surface modifications and optical properties which readers of this article can refer to [58-67]. However, it is important to discuss certain photophysical properties of QDs that influence their surface chemistry towards sensor development in order to convey a clearer understanding of the behavioural properties of different QD-based fluorescent probes for ROS/RNS. It is clearly evident that the most valuable property of a QDs fluorescent sensor is its ability to selectively detect the species of interest within the complex cellular environment or aqueous solution media. Particularly, the fluorescence stability of a QDs sensor is important for time-lapse detection. Hence, the characteristics of a fluorescence spectrophotometer (with reference to its excitation source and detection sensitivity), the QDs structure and composition and type of surface modifications are factors that influence the intensity of a measured QD fluorescence signal in the presence of the target species [68].

The generic photobleaching effect observed for a myriad of organic fluorophore dye molecules is a deterrent factor which not only contributes to phototoxicity but also limits the length of time for real-time monitoring. Hence, it is important that the choice of QD sensor must exhibit a strong resistance to photodegradation.

In theory, the fluorescence quantum yield of QDs is employed as the criterion to determine the quality of QDs. As the QDs are prone to surface defects due to surface dangling bonds which act as trap sites, QDs with high fluorescence quantum yields are desirable. 
Table 1. Summary of the analytical performance of various QDs fluorescent probes for ROS/RNS.

\begin{tabular}{|c|c|c|c|c|c|c|c|c|}
\hline QDs & $\begin{array}{l}\text { Capping } \\
\text { agent or } \\
\text { Coatinga }\end{array}$ & Species & $\begin{array}{c}\text { Cell } \\
\text { studies }\end{array}$ & $\begin{array}{c}\text { Fluorescence } \\
\text { signal }\end{array}$ & $\begin{array}{c}\text { Linear } \\
\text { range } \\
(\mathrm{nM})\end{array}$ & $\begin{array}{l}\text { LOD } \\
(\mathrm{nM})\end{array}$ & Selectivity & Ref. \\
\hline CdTe & MSA-HRP & $\mathrm{H}_{2} \mathrm{O}_{2}$ & - & Quenching & $\begin{array}{c}1000- \\
1000000\end{array}$ & 100 & NP & 93 \\
\hline $\mathrm{NP}$ & HRP-Cy5 & $\mathrm{H}_{2} \mathrm{O}_{2}$ & - & Enhancement & $10-100$ & 10 & $\mathrm{NP}$ & 95 \\
\hline CdTe/ZnS & MPA-AlTAPc & $\mathrm{H}_{2} \mathrm{O}_{2}$ & - & Enhancement & $1-16$ & 9.8 & Moderate & 96 \\
\hline $\mathrm{CdTe} / \mathrm{ZnS}$ & $\begin{array}{l}\text { MPA- } \\
\text { NiTAPc }\end{array}$ & $\mathrm{H}_{2} \mathrm{O}_{2}$ & - & Enhancement & $1-16$ & 4.4 & Good & 96 \\
\hline $\mathrm{CdTe} / \mathrm{ZnS}$ & $\begin{array}{c}\text { MPA- } \\
\text { ZnTAPc }\end{array}$ & $\mathrm{H}_{2} \mathrm{O}_{2}$ & - & Enhancement & $1-16$ & 2.2 & Poor & 96 \\
\hline CdTe & GSH-MPA & $\mathrm{H}_{2} \mathrm{O}_{2}$ & - & Quenching & $\begin{array}{c}0.0025- \\
0.040^{\mathrm{b}}\end{array}$ & $\begin{array}{c}0.001 \\
2^{\mathrm{b}}\end{array}$ & $\mathrm{NP}$ & 97 \\
\hline CdSe/ZnS & TGA-Cyt $c$ & $\mathrm{O}_{2} \bullet-$ & $\begin{array}{c}\text { HL-7702 } \\
\text { and } \\
\text { HeLa }\end{array}$ & Enhancement & $0-1200$ & $\mathrm{NP}$ & Good & 101 \\
\hline $\mathrm{CdTe} / \mathrm{ZnS}$ & $\begin{array}{c}\text { MPA- } \\
{\left[\mathrm{CoQH}_{2} \mathrm{C}_{1} \mathrm{~S}\right]_{2}}\end{array}$ & $\mathrm{O}_{2} \bullet-$ & HeLa & Quenching & $\begin{array}{c}1100- \\
4800000\end{array}$ & 600 & $\mathrm{NP}$ & 103 \\
\hline CdTe/ZnS & $\begin{array}{c}\text { MPA- } \\
{\left[\mathrm{CoQH}_{2} \mathrm{C}_{5} \mathrm{~S}\right]_{2}}\end{array}$ & $\mathrm{O}_{2} \bullet-$ & HeLa & Quenching & $\begin{array}{c}2300- \\
4410000\end{array}$ & 1800 & NP & 103 \\
\hline $\mathrm{CdTe} / \mathrm{ZnS}$ & $\begin{array}{c}\text { MPA- } \\
{\left[\mathrm{CoQH}_{2} \mathrm{C}_{10} \mathrm{~S}\right]_{2}}\end{array}$ & $\mathrm{O}_{2} \bullet-$ & HeLa & Quenching & $\begin{array}{c}3500- \\
4000000\end{array}$ & 2700 & $\mathrm{NP}$ & 103 \\
\hline $\mathrm{CdTe} / \mathrm{ZnS}$ & $\begin{array}{l}\text { MPA1- } \\
\text { CoTAPc }\end{array}$ & $\mathrm{O}_{2} \bullet-$ & - & Enhancement & $100-1000$ & 2.2 & Good & 104 \\
\hline $\mathrm{CdTe} / \mathrm{ZnS}$ & $\begin{array}{l}\text { MPA2- } \\
\text { CoTAPc }\end{array}$ & $\mathrm{O}_{2} \bullet-$ & - & Enhancement & $100-1000$ & 2.4 & Good & 104 \\
\hline CdTe/ZnS & GSH & $\cdot \mathrm{OH}$ & - & Quenching & $\mathrm{NP}$ & NP & $\mathrm{NP}$ & 112 \\
\hline CdTe & MPA & $\cdot \mathrm{OH}$ & - & Quenching & $100-700$ & 250 & Poor & 113 \\
\hline
\end{tabular}




\begin{tabular}{|c|c|c|c|c|c|c|c|c|}
\hline $\mathrm{CdTe}$ & TGA & $\cdot \mathrm{OH}$ & - & Quenching & $100-700$ & 97 & Poor & 113 \\
\hline $\mathrm{CdTe} / \mathrm{ZnS}$ & MPA & $\cdot \mathrm{OH}$ & - & Quenching & $100-700$ & 95 & Good & 113 \\
\hline CdTe/ZnS & GSH & $\cdot \mathrm{OH}$ & - & Quenching & $100-700$ & 85 & Good & 113 \\
\hline $\mathrm{CdSe} / \mathrm{ZnS}$ & Poly-CO ${ }_{2}^{-}$ & $\mathrm{HOCl}$ & HL60 & Quenching & NP & 250 & Good & 117 \\
\hline $\mathrm{CdTe}$ & Chitosan & $\mathrm{NO}$ & PIEC & Quenching & $480-76800$ & NP & NP & 128 \\
\hline $\mathrm{CdTe}$ & $\begin{array}{c}\text { TGA- } \\
\text { PNIPAM }\end{array}$ & $\mathrm{NO}$ & - & Quenching & NP & $\mathrm{NP}$ & Good & 129 \\
\hline CdSe & TEA & $\mathrm{NO}$ & - & Quenching & $\begin{array}{l}21200- \\
112000\end{array}$ & 302 & Good & 130 \\
\hline CdSe/ZnS & $\begin{array}{l}\text { Polymeth } \\
\text { acrylate }\end{array}$ & $\mathrm{NO}$ & - & Quenching & $0-33333333$ & 3 & $\mathrm{NP}$ & 131 \\
\hline CdSe & Chitosan & $\mathrm{NO}$ & - & Quenching & $460-55200$ & $\mathrm{NP}$ & NP & 132 \\
\hline $\mathrm{CdS}$ & PMMA & $\mathrm{NO}$ & & Quenching & $\begin{array}{c}14000- \\
9300000\end{array}$ & 1000 & NP & 133 \\
\hline CdSe & Chitosan & $\mathrm{NO}$ & - & Quenching & $\begin{array}{l}5000- \\
200000\end{array}$ & 1860 & Good & 134 \\
\hline CdSe & $\mathrm{mHP}$ & $\mathrm{NO}$ & - & Quenching & $30-700$ & 25 & Good & 135 \\
\hline $\mathrm{CdSe} / \mathrm{ZnS}$ & Cyclophane & $\mathrm{NO}$ & - & Quenching & $0.05-0.5^{b}$ & NP & $\mathrm{NP}$ & 137 \\
\hline $\mathrm{CdSe} / \mathrm{ZnS}$ & $\left.\mathrm{Fe}(\mathrm{DTCS})_{3}\right]^{3-}$ & $\mathrm{NO}$ & - & Enhancement & NP & 3000 & Good & 138 \\
\hline $\mathrm{CdTe}$ & MPA & $\mathrm{ONOO}^{-}$ & - & Quenching & $50-400$ & 72.4 & Poor & 142 \\
\hline $\mathrm{CdTe} / \mathrm{ZnS}$ & GSH-TGA & $\mathrm{ONOO}^{-}$ & - & Quenching & $50-400$ & 17.7 & Good & 142 \\
\hline CdTe/ZnS & MPA-TGA & $\mathrm{ONOO}^{-}$ & - & Quenching & $50-400$ & 12.6 & Moderate & 142 \\
\hline
\end{tabular}

aMSA $=$ Mercaptosuccinic acid, $\mathrm{HRP}=$ horseradish peroxidise, $\mathrm{MPA}=3$ mercaptopropionic acid, $\mathrm{TAPc}=$ tetra-amino phthalocyanine, GSH $=$ L-glutathione, Poly- $\mathrm{CO}_{2}^{-}=$Poly (maleic anhydride-alt-1-octadecene), PNIPAM = poly $(\mathrm{N}-$ isopropylacrylamide, TEA = triethanolamine, PMMA = Poly(methyl methacrylate), $\mathrm{mHP}=$ hyperbranched polyether, $\left.\mathrm{Fe}(\mathrm{DTCS})_{3}\right]^{3-}=$ tris(dithiocarbamato)iron III complex, PIEC $=$ Porcine iliac artery endothelial cells and NP $=$ not reported. bUnit recorded in \% vol. 
An additional factor which also influences the detection sensitivity of QDs is the excitation and emission wavelength. This particular factor is important for cellular detection since most biomolecules absorb light in the UV-vis spectrum. Therefore, longer wavelength light and lower energy are more desirable for excitation purposes than shorter wavelength light and higher energy due to greater photodamage induced by the latter $[69,70]$. Table 1 provides a summary of the analytical performance of different QD probes for ROS/RNS.

\section{QDs versus organic fluorescent dyes}

It is important to note that the fluorescence properties of QDs are influenced by their surface state, thus it is expected that any physical or chemical interactions between their surfaces and the chemical species of interest will influence the efficiency of the electron-hole recombination process. It is a well established concept that by conjugating QDs to appropriate molecules or biomolecules of interest, specific detection of analytes can be achieved. However, the emergence of QD fluorescent probes for ROS/RNS as compared with organic fluorescent dyes is still very limited. This is partly due to the difficulty in manufacturing photostable QD-bioconjugate probes and moreover the inability to develop adequate surface functionalization of the QDs for specific detection of the ROS/RNS has been a major obstacle. However, it should be noted that the ability of QDs to exhibit greater resistance to photobleaching, narrower emission spectral line-width and brighter fluorescence, are unique advantages of these sensors over organic dyes. 
To date, most of the fluorescent probes reported for ROS/RNS are organic dyebased and can be classified as "redox sensitive" and "non-redox sensitive" probes [14].The most commonly used are the "redox sensitive" dyes which are able to undergo hydrolysis due to their esterified derivatives, hence they can penetrate into cells and become oxidized in the presence of the ROS/RNS to fluorescent products [14]. However, despite their widespread use, they lack specificity for any one species and the fluorescence information is impeded by various chemical reactions. Nonredox fluorescent probes represent the newer generation of organic dyes and were developed to overcome the multiple problems associated with redox sensitive dyes. The fluorescence of the probes is generally protected by a blocking group which is then released by nucleophilic attack by the reactive species. Thus the oxidized form of the blocking group is unmasked and the oxidized form of the fluorophore remains the same [14]. However, the kinetic reactions of these probes in cellular environments are still unclear and have shown promise for selectivity but not specificity. Presently, there are no organic dye probes that can quantify cellular production of ROS/RNS but a breakthrough in the quantification of ROS in cells using QDs has been reported as discussed below.

\section{QDs fluorescent probes to detect ROS}

\subsection{Hydrogen peroxide}

Hydrogen peroxide is one of the major ROS in living systems and it is known to play an important role as a secondary messenger in normal cell signal transduction [7173]. It can act both as a byproduct from other ROS and also as a precursor for the 
production of other ROS [74]. Amongst the family of $\mathrm{ROS}, \mathrm{H}_{2} \mathrm{O}_{2}$ is known to be relatively stable, but its excessive production induces oxidative stress damage which is affiliated to cancer and aging. Hence, molecular probes for the detection of $\mathrm{H}_{2} \mathrm{O}_{2}$ in various sample matrices are of considerable interest. Although there are numerous probes such as colorimetric sensors [75-78], electrochemical sensors [79-81] and various fluorescent probes [82-85] for $\mathrm{H}_{2} \mathrm{O}_{2}$, QD probes for $\mathrm{H}_{2} \mathrm{O}_{2}$ are very limited and their development has not received much attention. Apart from the few QD fluorescent probes which are capable of specific detection of $\mathrm{H}_{2} \mathrm{O}_{2}$, a number of $\mathrm{H}_{2} \mathrm{O}_{2}$-sensitive QD fluorescent probes for the detection of various analytes have also been developed [86-90]. However, the $\mathrm{H}_{2} \mathrm{O}_{2}$-sensitive QD fluorescent probes are not designed specifically to detect $\mathrm{H}_{2} \mathrm{O}_{2}$, but the presence of $\mathrm{H}_{2} \mathrm{O}_{2}$ in the detection system is usually employed to mediate the detection of other target analytes.

Presently, there are no detailed reports of QD probes for the detection of $\mathrm{H}_{2} \mathrm{O}_{2}$ in cellular environments. A report described by Mancini et al. showed that $\mathrm{H}_{2} \mathrm{O}_{2}$ which was generated from phagocytic cells quenched the fluorescence of poly(acrylic acid) graft dodecylamine core-shell CdSe/CdS/ZnS QDs [91]. Although the work described in ref. [91] was not directed towards sensor development, it gives a glimpse of scientific hope that with well calculated designs, intracellular or extracellular sensing of $\mathrm{H}_{2} \mathrm{O}_{2}$ can be achieved using QDs. In general, development of novel QD probes for $\mathrm{H}_{2} \mathrm{O}_{2}$ detection in cellular environments is still a major challenge. We believe this difficulty has been hampered by the complexity involved in the design of such probe. For example, for intracellular detection, $\mathrm{H}_{2} \mathrm{O}_{2}$ is known not to react directly with fluorescent probes but normally requires the presence of an 
enzyme or metal catalyst bound to the fluorophore to influence the fluorescence signal of the fluorophore and also to provide specificity [14,92]. In addition, oxidation of $\mathrm{H}_{2} \mathrm{O}_{2}$-sensitive fluorescent probes by competitive radicals and other species usually leads to complications and false positive interpretations of experimental data. Hence, if a QD fluorescent probe for recognition of $\mathrm{H}_{2} \mathrm{O}_{2}$ is to be developed in cells, it will require elegant chemistry accompanied with sophisticated and well manipulated designs.

Alternatively, a number of QDs fluorescent probes for aqueous phase detection of $\mathrm{H}_{2} \mathrm{O}_{2}$ have been developed. Yuan et al. demonstrated in their work that by employing a mercaptosuccinic acid (MSA)-capped CdTe QD-enzyme hybrid system, a sensor can be developed for $\mathrm{H}_{2} \mathrm{O}_{2}$ [93]. The concept involved the catalytic coupling of horseradish peroxidase (HRP) on the QDs surface in addition to the presence of hydroquinone $\left(\mathrm{H}_{2} \mathrm{Q}\right)$ in the detection system to form a $\mathrm{H}_{2} \mathrm{Q}-\mathrm{HRP}-\mathrm{QD}$ hybrid system. HRP is a redox enzyme containing the heme group and is able to catalyze the chemical reduction of $\mathrm{H}_{2} \mathrm{O}_{2}$ due to the transfer of an electron which converts $\mathrm{Fe}^{2+}$ in the heme of HRP to $\mathrm{Fe}^{3+}$ [94]. This implies that the coupling of HRP on the QD surface could enhance the specific fluorescence response to $\mathrm{H}_{2} \mathrm{O}_{2}$. It was demonstrated that $\mathrm{H}_{2} \mathrm{O}_{2}$ effectively quenched the fluorescence of the enzyme-QD hybrid system and a good detection limit was achieved over a wide linear range. However, the detection mechanism was not elucidated and a selectivity study for the sensor was not provided, which thus indicate that the affinity of the sensor to specifically detect $\mathrm{H}_{2} \mathrm{O}_{2}$ without interference from other species in solution was unknown. 

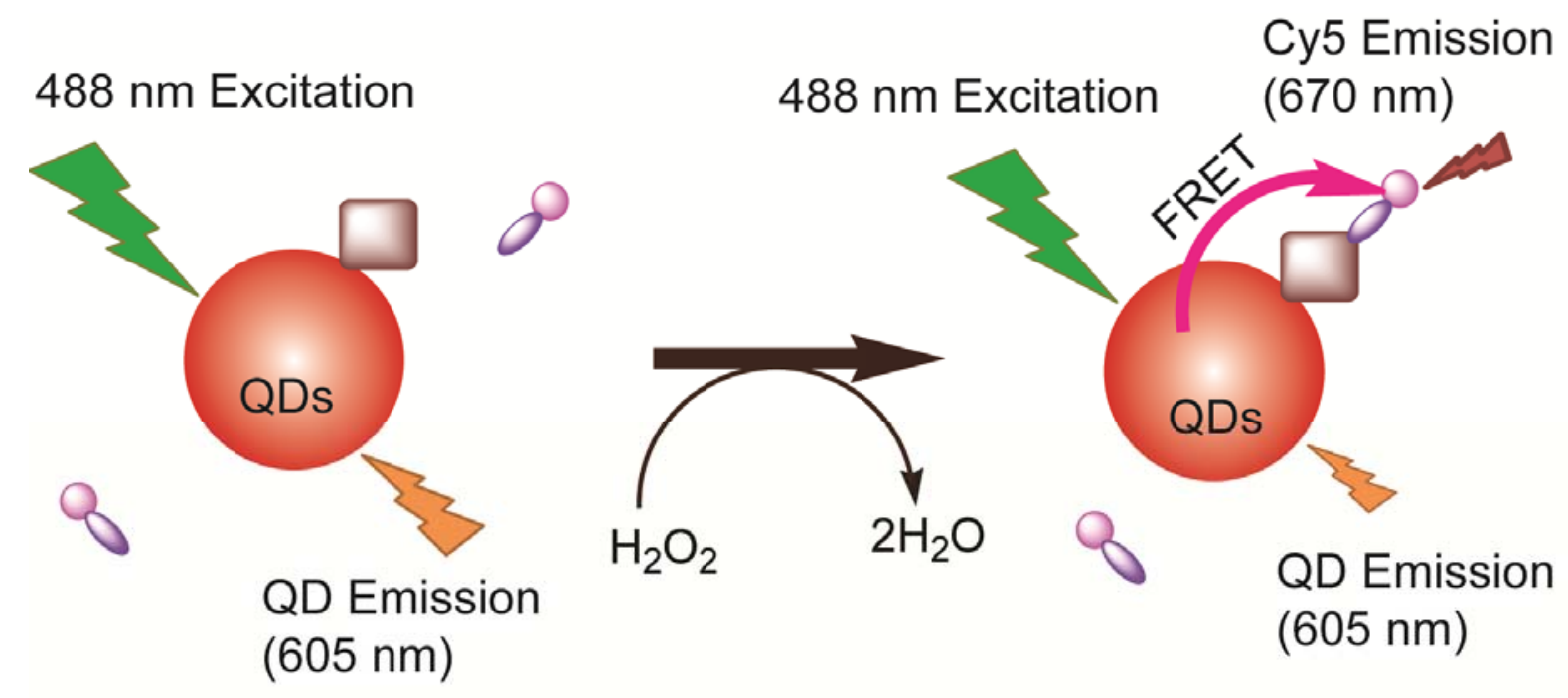

HRP

tyamide labeled Cy5

Scheme 1. Schematic illustration of the FRET process between HRP-605QDs (donor) and tyramide Cy5 (acceptor). Adapted from ref. [95]. 


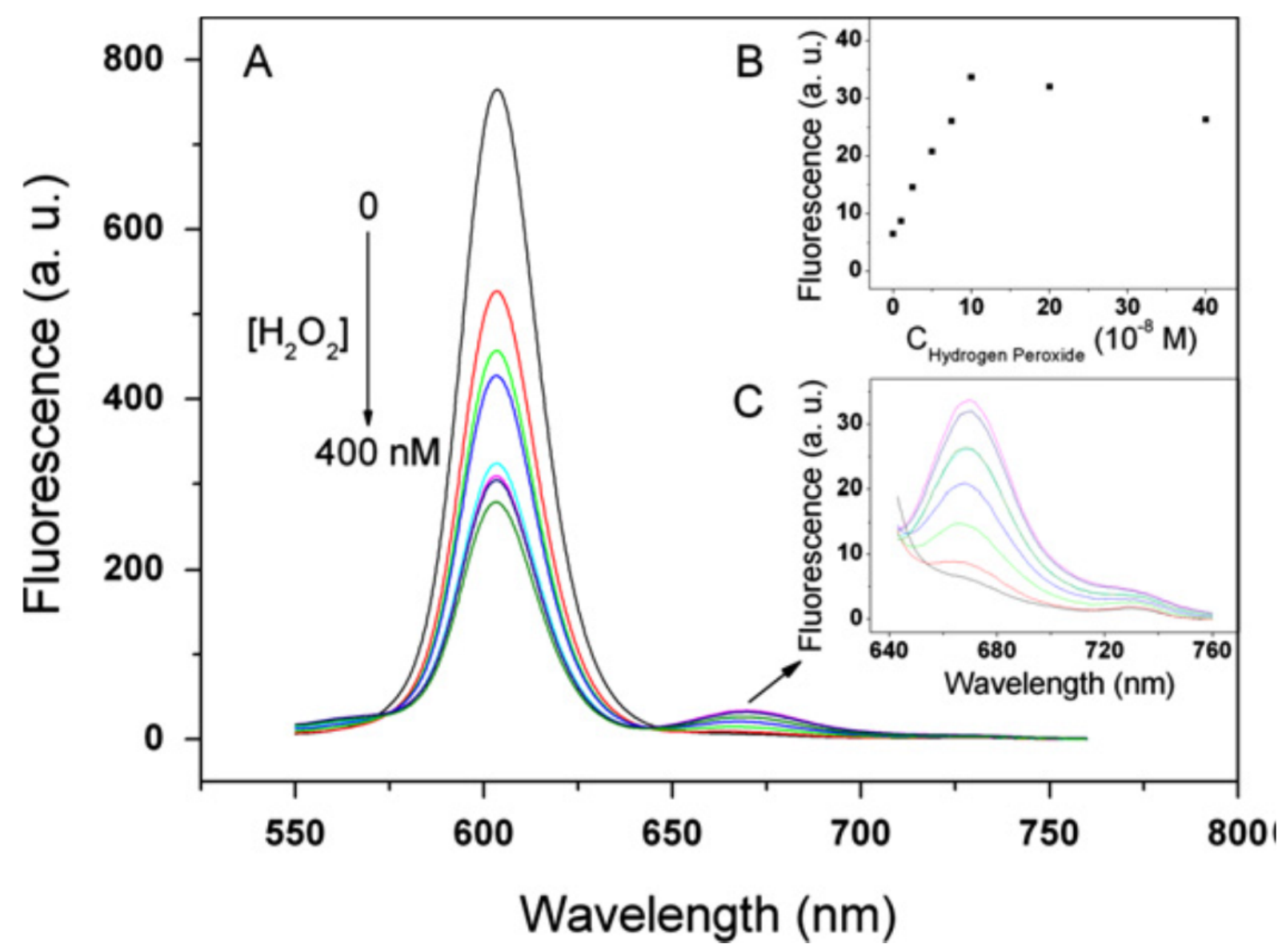

Fig. 1. (A) Fluorescence spectra of the 605 QDs andCy5 based FRET system at different concentrations of $\mathrm{H}_{2} \mathrm{O}_{2}$. (B) The amplificatory fluorescence spectra of the Cy5 based FRET system at different concentrations of $\mathrm{H}_{2} \mathrm{O}_{2}$. (C) The relationship between the concentration of $\mathrm{H}_{2} \mathrm{O}_{2}$ and the $\mathrm{Cy} 5$ fluorescence intensity at $670 \mathrm{~nm}$. Reproduced from ref. [95]. Copyright (2013), with permission from Elsevier. 
A novel method to detect $\mathrm{H}_{2} \mathrm{O}_{2}$ based on Förster resonance energy transfer (FRET) reactions was proposed by Huang et al. [95]. As shown in Scheme 1, HRP was firstly conjugated to QDs (with emission wavelength of $605 \mathrm{~nm}$ ) and then subsequently employed as a catalyst for coating the QDs surface with a tyramide labelled Cy5 amplification reagent. The innovative method displayed an overlap of the emission of the QDs (donor) with the absorption spectrum of Cy5 (acceptor) resulting in a HRP-conjugated QDs/Cy5 FRET system. It was found that as the concentration of added $\mathrm{H}_{2} \mathrm{O}_{2}$ increased, the fluorescence intensity of $\mathrm{Cy} 5$ increased while the fluorescence of the QD decreased simultaneously, resulting in the transfer of energy from the QD to Cy5 (Fig. 1). This work demonstrated a clear understanding of the reaction mechanism. A narrow linear regression range and high sensitivity were obtained but the selectivity of the developed QDs-Cy5 FRET sensor was not reported.

Recently, three different metal $(\mathrm{M}=\mathrm{Al}, \mathrm{Ni}$ and $\mathrm{Zn})$ tetraamino-phthalocyanines (MTAPc) were synthesized and conjugated to 3-mercaptopropionic acid (MPA)capped CdTe/ZnS quantum dots to form different QDs-MTAPc nanoprobes for the comparative fluorescence turn-ON sensor for $\mathrm{H}_{2} \mathrm{O}_{2}$ [96]. It was shown that upon conjugation of the MTAPc to the QDs, the fluorescence of the QDs was quenched due to FRET from the QDs (donor) to the MTAPc (acceptor) and subsequently recovered upon varying concentration of $\mathrm{H}_{2} \mathrm{O}_{2}$ (Fig. 2A-2C). This resulted from the obstruction of the FRET process between the QDs and MTAPcs (Scheme 2). However, how the FRET process was disrupted by $\mathrm{H}_{2} \mathrm{O}_{2}$ was not fully elucidated. The order of sensitivity of the probe was: QDs-ZnTAPc > QDs-NiTAPc > QDs- 


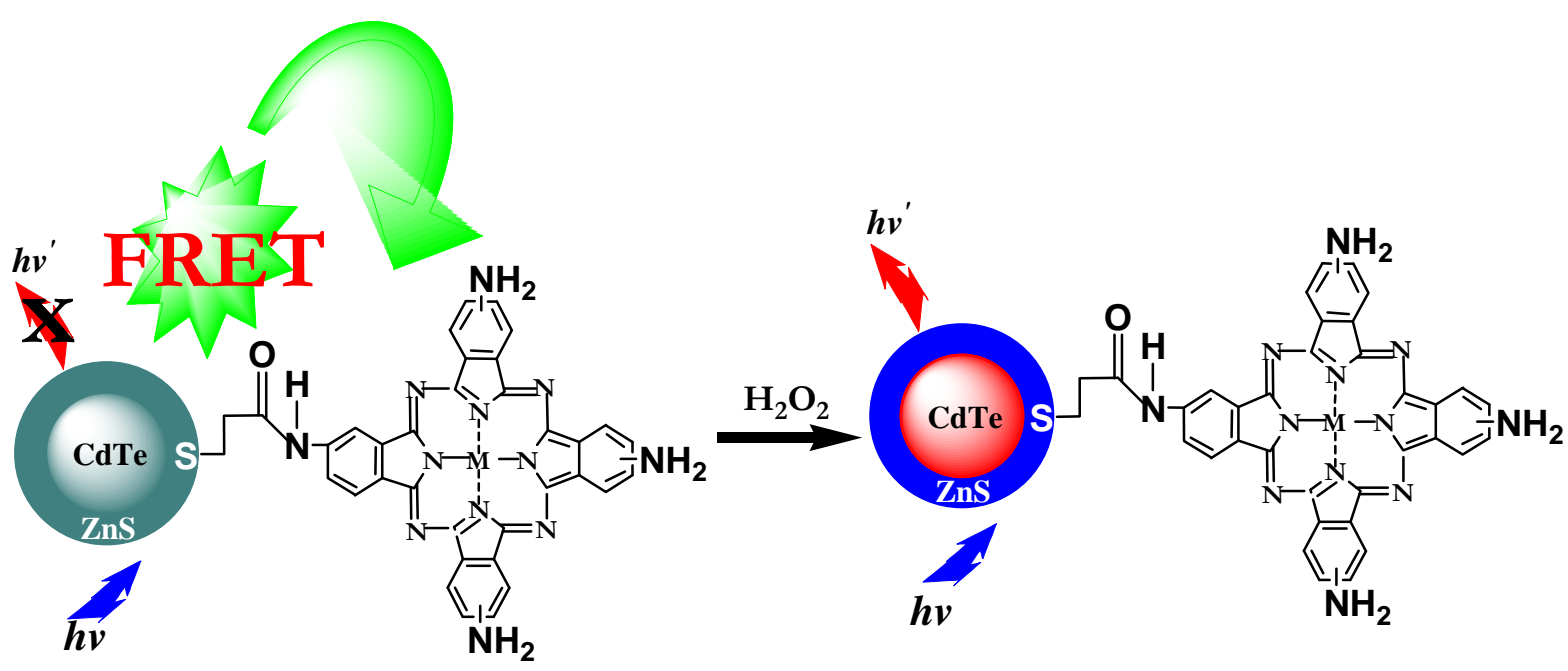

Fluorescence

Fluorescence

"Switched OFF"

$$
M=\text { ClAl, Ni and Zn }
$$

Scheme 2. Schematic representation showing the preparation of QDs and QDsMTAPc nanoconjugate. Adapted from ref. [96] with kind permission from Springer Science and Business Media. 

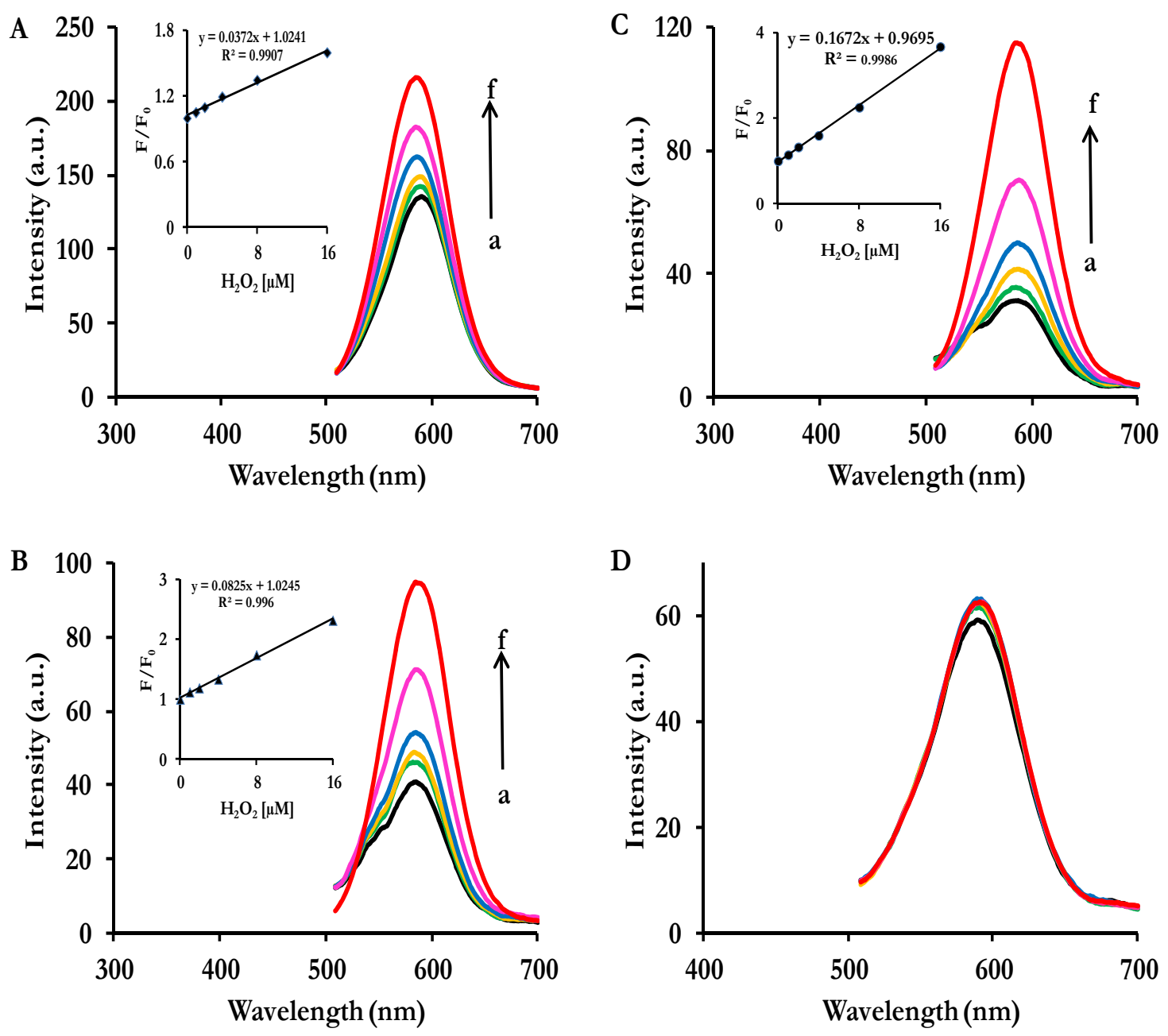

Fig. 2. Fluorescence emission spectra of (A) QDs-AlTAPc, (B) QDs-NiTAPc, (C) QDsZnTAPc and (D) QDs- $\mathrm{H}_{2}$ TAPc upon addition of varying concentration of $\mathrm{H}_{2} \mathrm{O}_{2}$. Inset: calibration curve of $\mathrm{F} / \mathrm{F}_{0}$ versus $\mathrm{H}_{2} \mathrm{O}_{2}$ concentration. Adapted from ref. [96] with kind permission from Springer Science and Business Media. 
AlTAPc while the order of selectivity was: QDs-NiTAPc > QDs-AlTAPc > QDsZnTAPc. A very low limit of detection (LOD) was reported. It was demonstrated that the QDs-unmetallated phthalocyanine conjugate did not show any fluorescence response to $\mathrm{H}_{2} \mathrm{O}_{2}$ (Fig. 2D). Also, from electron density functional theorem estimation, the higher electron density on the QDs-NiTAPc surface was attributed to its high selectivity for $\mathrm{H}_{2} \mathrm{O}_{2}$ in the presence of other biologically active species.

In a recent article, a sensor was developed for $\mathrm{H}_{2} \mathrm{O}_{2}$ based on the addition of an electron-donor ligand (L-glutathione $(\mathrm{GSH})$ ) to effect the enhancement of the fluorescence intensity of MPA-capped CdTe QDs in an automated flow system, where the fluorescence of the GSH-MPA-CdTe QDs system was quenched and linearly proportional to the concentration of $\mathrm{H}_{2} \mathrm{O}_{2}$ [97]. It was proposed that the presence of $\mathrm{H}_{2} \mathrm{O}_{2}$ enhanced the oxidation of glutathione to glutathione disulfide and thus a dramatic decrease in the available number of $\mathrm{SH}$ groups (which would allow the strong Cd-S covalent bond between the QDs surface and GSH) was observed. The proposed sensor was applied to detect $\mathrm{H}_{2} \mathrm{O}_{2}$ in contact lens preservation solution with good recoveries. Similar to other QDs probes discussed above (with the exception of [96]), no selectivity studies for $\mathrm{H}_{2} \mathrm{O}_{2}$ were conducted for this sensor.

\subsection{Superoxide radical}

The superoxide radical is a well known ROS that reacts with relatively few biological molecules and it is both a weak reducing species and weak oxidising species $[\mathbf{1 4}, \mathbf{9 8}-$ 100]. Similar to $\mathrm{H}_{2} \mathrm{O}_{2}, \mathrm{O}_{2} \bullet-$ can serve as a precursor for the production of other ROS and it is a product of one-electron reduction of molecular oxygen [74]. Its excessive 
production is of great physiological and pathological concern, hence the need to develop suitable probes for its detection is of paramount interest. A CdSe/ZnS QDsCytochrome $c$ bioconjugate probe that displayed excellent sensitivity and selectivity in aqueous solution for $\mathrm{O}_{2} \bullet-$ over a wide linear range was developed by Li et al. [101]. Cytochrome $c$ is a heme-containing redox protein and is preferably used as a recognition entity for specific detection of $\mathrm{O}_{2} \bullet$ [102]. Due to its ability to effectively couple to oppositely charged molecules, successful bioconjugation to QDs has been exploited to target $\mathrm{O}_{2} \bullet$. In addition to the effectiveness of the probe, intracellular sensing of $\mathrm{O}_{2} \bullet$ was also described in the paper. For the aqueous phase detection, the construction of the probe was based on a two-way principle. Firstly, it was reported that the oxidised Cytochrome $c$ quenched the fluorescence of the negatively charged QDs, thereafter, the generated $\mathrm{O}_{2}{ }^{\bullet}-$ from pyrogallol assay led to the reduction of the oxidised Cytochrome $c$ and the fluorescence of the QDs was progressively recovered in the presence of the reduced Cytochrome $c$ (Fig. 3). Selectivity studies showed that the presence of other ROS and biological molecules (at a concentration higher than $\mathrm{O}_{2}{ }^{\bullet-}$ ) did not interfere with the detection of $\mathrm{O}_{2}{ }^{\bullet-}$, suggesting a high selectivity for $\mathrm{O}_{2}{ }^{\bullet}$. Based on these results, the QDs-Cytochrome $c$ probe was successfully employed to sense $\mathrm{O}_{2} \bullet$ (which was generated from stimulated human liver (HL-7702) and HeLa cells) in living cells with high sensitivity as shown by the overall mechanism in Scheme 3, [101]. This work practically demonstrated the real life application of the probe in biological systems.

Further aqueous phase and intracellular detection of $\mathrm{O}_{2} \bullet-$ was described by Qin et al. [103]. Three reduced redox-active coenzyme disulfide forms of $\left(\left[\mathrm{CoQH}_{2} \mathrm{C}_{\mathrm{n}} \mathrm{S}\right]_{2}\right.$, 


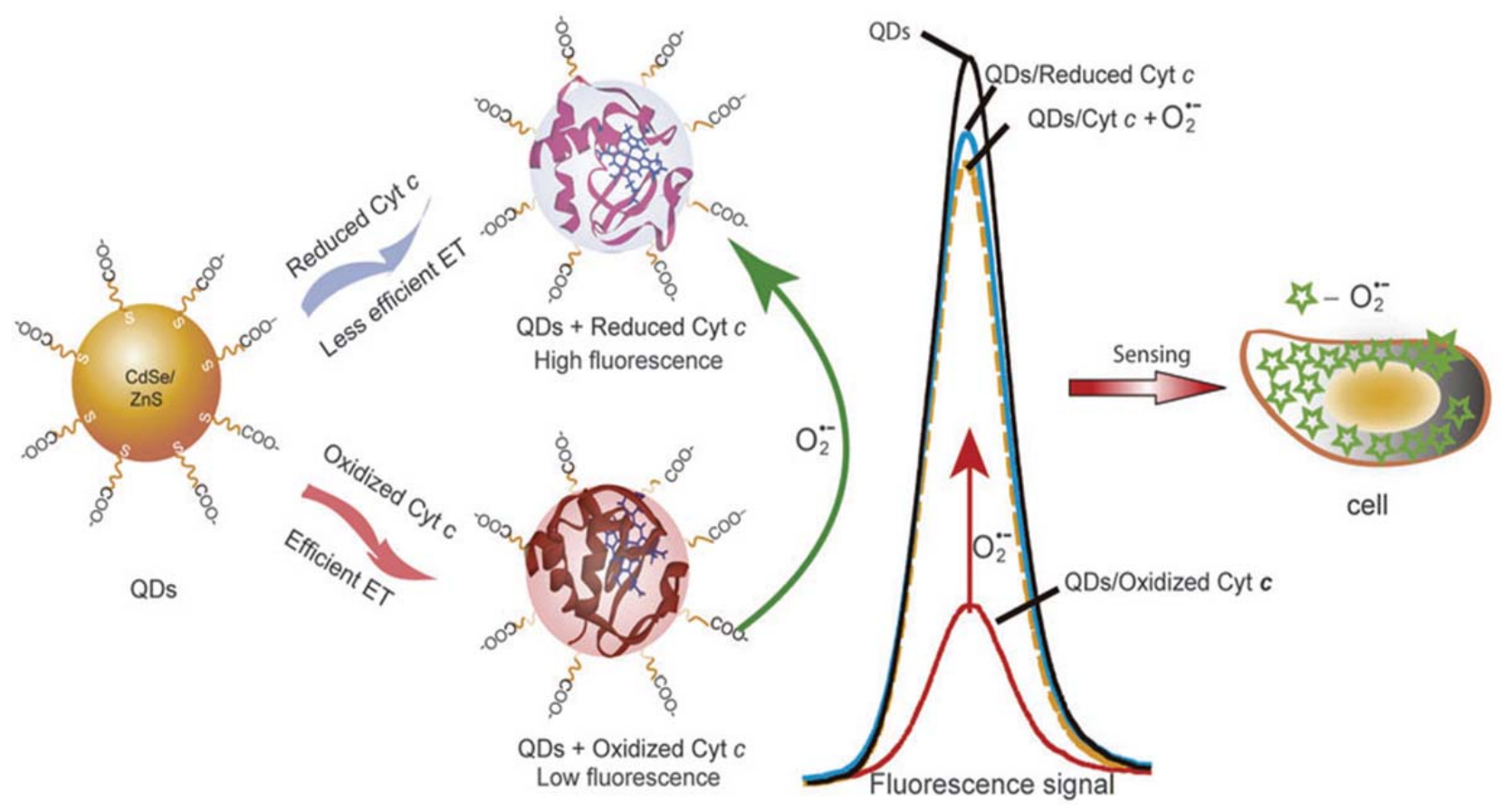

Scheme 3. Schematic diagram of fluorescence modulation by negatively capped CdSe/ZnS QD-Cytochrome $c$ system. Oxidized Cytochrome c efficiently quenched the fluorescence of negatively capped CdSe/ZnS QDs, and the QD-reduced Cytochrome $c$ bioconjugates maintained a higher luminescence efficiency than the QD-oxidized Cytochrome $c$ layer. The fluorescence intensity of QD-oxidized Cytochrome $c$ was significantly restored in the presence of $\mathrm{O}_{2}{ }^{\bullet-}$ which can be used to sense the $\mathrm{O}_{2}{ }^{\bullet-}$ in HeLa cells and normal human liver (HL-7702) cells. ET = energy transfer. Reproduced from Ref. [101] with permission from The Royal Society of Chemistry. 


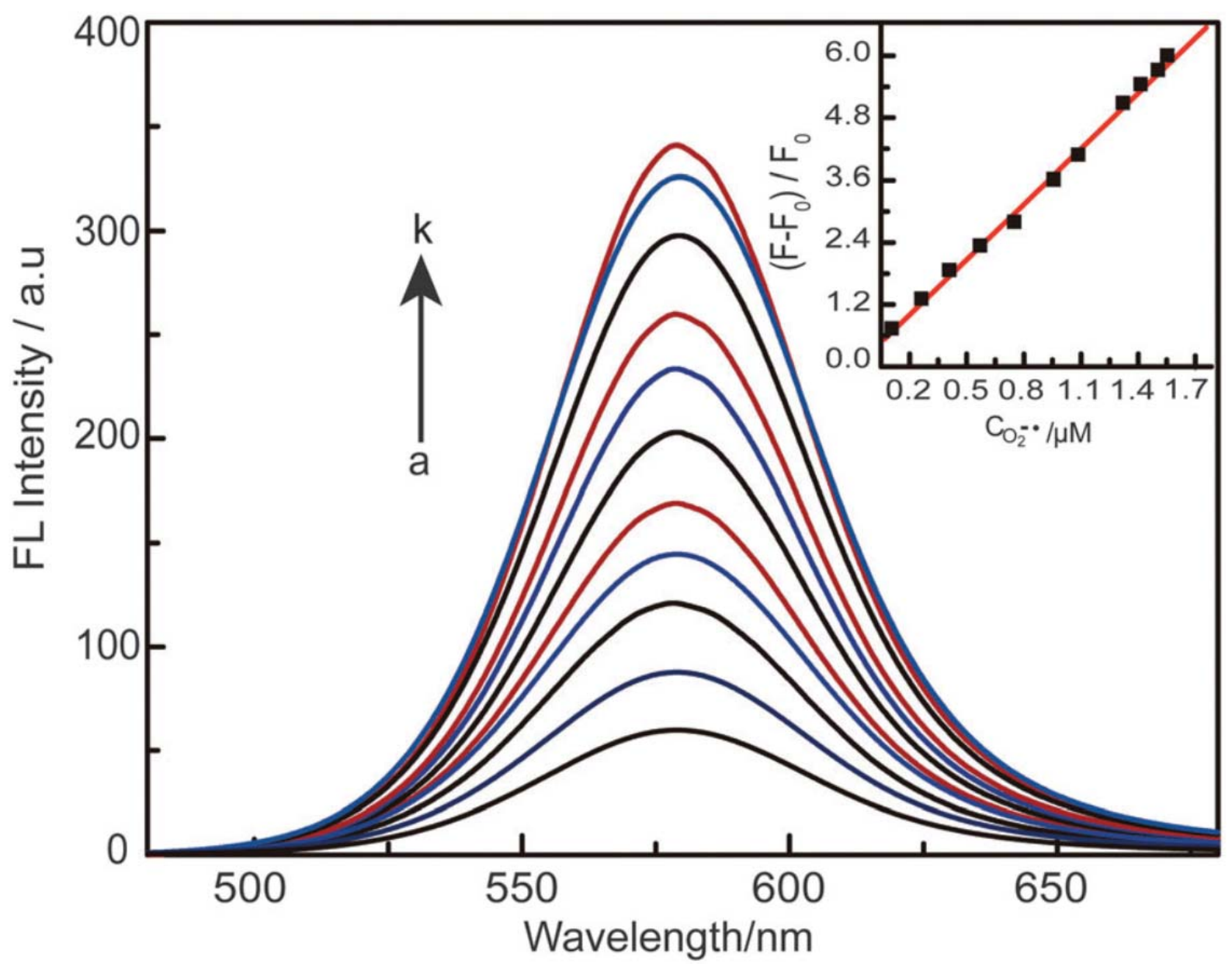

Fig. 3. Fluorescence intensity of negatively capped QDs-Cyt c system with varying $\mathrm{O}_{2} \bullet$ concentrations (from a to $\mathrm{k}: 0-1.2 \mu \mathrm{M}$ ). Reproduced from Ref. [101] with permission from The Royal Society of Chemistry. 
having the ubiquinone structure of 2,3-dimethoxy-5-methyl-1,4-benzoquinone with different derivatized mercaptoalkyl side chain lengths at the 6-position ( $\mathrm{n}=1$, QDs$\left[\mathrm{CoQH}_{2} \mathrm{C}_{1} \mathrm{~S}\right]_{2}, \quad \mathrm{n}=5, \quad \mathrm{QDs}-\left[\mathrm{CoQH}_{2} \mathrm{C}_{5} \mathrm{~S}\right]_{2}$ and $\mathrm{n}=10$, QDs- $\left.\left[\mathrm{CoQH}_{2} \mathrm{C}_{10} \mathrm{~S}\right]_{2}\right)$ were synthesized and immobilised onto the surface of MPA-capped CdTe/ZnS QDs. The electrochemically reduced modified QDs-[CoQH $\left.\mathrm{C}_{2} \mathrm{~S}\right]_{2}$ were investigated for their fluorescence response towards $\mathrm{O}_{2} \bullet$ in aqueous solution. Results showed that the length of the akyl linker chain influenced the extent of fluorescence sensitivity of the QDs by $\mathrm{O}_{2} \bullet$ and the order followed: QDs-[CoQH $\left.\mathrm{C}_{2} \mathrm{~S}\right]_{2}>$ QDs-[CoQH $\left.\mathrm{C}_{5} \mathrm{~S}\right]_{2}>$ QDs$\left[\mathrm{CoQH}_{2} \mathrm{C}_{10} \mathrm{~S}\right]_{2}$. Further studies to confirm the fluorescence quenching was carried out using bare QDs with results indicating that $\mathrm{O}_{2} \bullet-$ had a negligible effect, hence the confirmation of the fluorescence quenching of modified QDs- $\left[\mathrm{CoQH}_{2} \mathrm{C}_{n} \mathrm{~S}\right]_{2}$ by $\mathrm{O}_{2}{ }^{\bullet}$. The mechanism of reaction was described based on the ability of $\mathrm{O}_{2} \bullet$ to oxidize the reduced modified QDs- $\left[\mathrm{CoQH}_{2} \mathrm{C}_{n} \mathrm{~S}\right]_{2}$ back to the oxidized modified QDs-[CoQC $\left.\mathrm{C}_{n}\right]_{2}$. For the fluorescence imaging of $\mathrm{O}_{2} \bullet$ in cellular environments, HeLa cells were stimulated with phorbol myristate acetate (PMA) to generate $\mathrm{O}_{2} \bullet$. It was found that the reduced modified QDs-[CoQH $\left.\mathrm{C}_{\mathrm{n}} \mathrm{S}\right]_{2}$ gave bright fluorescence and responded to changes in the concentration of $\mathrm{O}_{2} \bullet$ - in living cells while the oxidized modified QDs$\left[\mathrm{CoQC} \mathrm{n}_{\mathrm{S}}\right]_{2}$ displayed poor fluorescence under identical conditions. The results of the cellular studies clearly complemented the observations of the fluorescence quenching studies. However, based on these excellent studies, the ability of the proposed probe to selectively detect $\mathrm{O}_{2} \bullet-$ without interferences from other biological species of interest was not proven. 
A novel nanosensor for $\mathrm{O}_{2}{ }^{\bullet-}$ was recently reported [104]. The sensor was designed by conjugating MPA-CdTe@ZnS QDs to CoTAPc to form a QDs-CoTAPc nanoconjugate system. Prior to aqueous phase detection of $\mathrm{O}_{2}{ }^{\bullet-}$, the stability of $\mathrm{O}_{2}{ }^{\bullet-}$ was effectively studied using Electron Paramagnetic Resonance (EPR) spectroscopy from $0-2.5 \mathrm{hr}$ in the experimental medium employed for the detection of $\mathrm{O}_{2}{ }^{\bullet}$. It was proven that within the experimental time employed for the detection $\mathrm{O}_{2}{ }^{\bullet-}$, the EPR spectra of $\mathrm{O}_{2} \bullet-$ did not degrade. This study clearly demonstrated for the first time the unique stability of $\mathrm{O}_{2}{ }^{\bullet}$ in the experimental medium used for its detection. The conjugation of the QDs to CoTAPc resulted in the "switching OFF" of the fluorescence of the QDs due to FRET and the presence of varying concentrations of $\mathrm{O}_{2} \bullet-$ progressively "switched $\mathrm{ON}^{\prime}$ the fluorescence of the QDs, thus disrupting the FRET process. However, a very low detection limit and high selectivity for $\mathrm{O}_{2}{ }^{\bullet-}$ was observed over other coexisting biologically active species. Studies to show how the obstruction of the FRET process was influenced by $\mathrm{O}_{2} \bullet-$ was not reported in this work. However, a subsequent study by the same authors elucidates the reaction mechanism between QDs-MTAPc and target analytes as reported in literature [105], where they proposed that axial ligation of the analytes onto the conjugated MTAPc ring influences the obstruction of the FRET process between the QDs and MTAPcs.

\subsection{Hydroxyl radical}

The hydroxyl radical is a potent oxidant and the most reactive of the class of ROS. It is primarily involved in the degradation of biomolecules, such as lipids, DNA, and proteins in cells. Consequently it plays a key role in cancer treatment and radiation 
therapy [106]. However, due to its high reactivity and strong oxidative power, it is also known to induce various pathological and physiological dysfunctions. In vivo formation of $\bullet \mathrm{OH}$, may involve various multiple reactions, such as the reaction of $\mathrm{HOCl}$ with $\mathrm{O}_{2} \bullet$ - and metal ions with $\mathrm{H}_{2} \mathrm{O}_{2}$ [107]. Generally, it is widely documented that $\bullet \mathrm{OH}$ is generated in biological systems by the well known Fenton reaction as follows [108,109]:

$\mathrm{Fe}^{2+}+\mathrm{H}_{2} \mathrm{O}_{2} \rightarrow \mathrm{Fe}^{3+}+\cdot \mathrm{OH}+\mathrm{OH}^{-}$

The reduction of $\mathrm{Fe}^{3+}$ by $\mathrm{O}_{2}{ }^{\bullet-}$ is a source of $\mathrm{Fe}^{2+}$ required for the Fenton reaction, which thus leads to the production of $\bullet \mathrm{OH}$ (from $\mathrm{O}_{2} \bullet$ and $\mathrm{H}_{2} \mathrm{O}_{2}$ ) and this is potentially present in aerobic cells. The reaction is popularly known as the Fe(II,III)catalyzed Haber-Weiss reaction [110]. The incorporation of metal chelators, such as ethylene diamine tetraacetic acid (EDTA), results in the reaction with $\mathrm{Fe}^{2+}$ to form $\mathrm{Fe}^{2+}$-EDTA and this serves to eliminate site-specific damage by $\mathrm{Fe}^{2+}$ on the probe which thus enables effective measurement of $\bullet \mathrm{OH}$ [111]. Generally speaking, developing suitable probes for $\bullet \mathrm{OH}$ is an extremely difficult challenge due to its instability and short lifetime. It is therefore not a surprise that QD fluorescent probes for $\bullet \mathrm{OH}$ are relatively rare. In fact, detection of $\bullet \mathrm{OH}$ in cellular matrixes using QD fluorescent probes has never been reported in literature. In a work performed by $\mathrm{Wu}$ et al., a GSH-capped CdTe QDs-Fenton hybrid system displayed fluorescence sensitivity to $\bullet \mathrm{OH}$ [112]. The fluorescence quenching process was attributed to electron transfer from the conduction band of the QDs to the unoccupied band of - $\mathrm{OH}$. However, the work did not demonstrate practical selectivity testing and the limit of detection and other analytical parameters were not reported. In a recent 
article, a comparative study was carried out using four different types of QDs, composed of thioglycolic acid (TGA)-CdTe, MPA-CdTe, MPA-CdTe/ZnS and GSH$\mathrm{CdTe} / \mathrm{ZnS}$ QDs for the sensitive and selective fluorescence detection of $\bullet \mathrm{OH}$ in aqueous solution [113]. $\bullet \mathrm{OH}$ was reportedly generated from a $\mathrm{Fe}^{2+}-\mathrm{EDTA} / \mathrm{H}_{2} \mathrm{O}_{2-}$ ascorbic acid Fenton hybrid system which thus mimicked the generation of $\bullet \mathrm{OH}$ from biological foot-printing of proteins. The sensitivity of the sensor followed the order: GSH-CdTe@ZnS > MPA-CdTe@ZnS > TGA-CdTe > MPA-CdTe QDs. The core-shell QDs were shown to be more selective towards the detection of $\bullet \mathrm{OH}$ than the core QDs when examined in the presence of other interferent species. Even the presence of the Fenton reactant and products were shown not to interfere with the probe. The mechanism of detection was dynamic in nature and was based on electron transfer from the QDs to ${ }^{\bullet} \mathrm{OH}$ to produce hydroxyl anions.

\subsection{Hypochlorous acid}

$\mathrm{HOCl}$ is known to play a key role in inflammatory response and myeloperoxidase, a neutrophil enzyme is known to be a source of its production $[\mathbf{1 1 4 , 1 1 5 ] . ~ I n ~ c o n t r a s t ~ t o ~}$ other ROS, an exclusive two-electron oxidation process is normally attributed to the biological reactivity of $\mathrm{HOCl}[\mathbf{1 1 6}]$, while a non-radical mechanism is associated with its oxidative effect on $\mathrm{HOCl}$-sensitive probes. $\mathrm{HOCl}$ also exists in equilibrium with hypochlorite $\left(\mathrm{ClO}^{-}\right)$at physiological $\mathrm{pH}$. But the major problem associated with its detection is the difficulty in distinguishing between the peroxidation of various fluorescent probes and the response of $\mathrm{HOCl}$ [14]. In contrast, the high reactivity of $\mathrm{HOCl}$ is a major advantage for the design of fluorescent probes that react poorly 
with other ROS and radicals. However, if the probe response is slow, its detection is easily interfered with by scavengers such as components of buffer solutions and biological molecules [14]. An excellent study described by Yan et al. showed that QDs coated with certain organic capping ligands can be exploited for the fluorescence detection of $\mathrm{HOCl}$ in aqueous solution and in cells [117]. By varying the sensitivity of four types of CdSe/ZnS QDs coated with methylamino, sulphide, hydrocarbon and carboxylate layers, it was found that QDs-poly- $\mathrm{CO}_{2}{ }^{-}$displayed higher fluorescence sensitivity for the detection of $\mathrm{HOCl}$ than the other modified QDs with methylamino, sulphide or hydrocarbon functionalities. The mechanism of detection was attributed to the ability of $\mathrm{HOCl}$ to diffuse through the negative layer of the polymer coating and induce oxidative etching on the surface of the QDs. Selectivity studies showed that the fluorescence of the QDs probe was superior for $\mathrm{HOCl}$ and was unpertubed by the presence of other ROS. Intracellular fluorescence sensing using the proposed probe was confirmed in HL60 cells treated with HClO. As shown in Fig. 4, fluorescence imaging confirmed the fluorescence quenching effect of $\mathrm{HOCl}$ on the probe (Fig $5 \mathrm{C}$, upper panel) in a period of $30 \mathrm{~min}$ while the nontreatment of $\mathrm{HOCl}$ with the cell did not display any apparent fluorescence quenching of the probe (Fig 5C, lower panel). This work clearly demonstrated the effectiveness of using QDs-based probes for $\mathrm{HOCl}$ detection both in cells and aqueous environments.

A polymer microbead-conjugated CdSe QDs sensor for the in vivo and in vitro quantification of endogenous $\mathrm{HOCl}$ produced by leukocytes was reported by Yang et al. [118]. A microbead of diameter $2 \mu \mathrm{m}$ was chosen to enable internalization of 


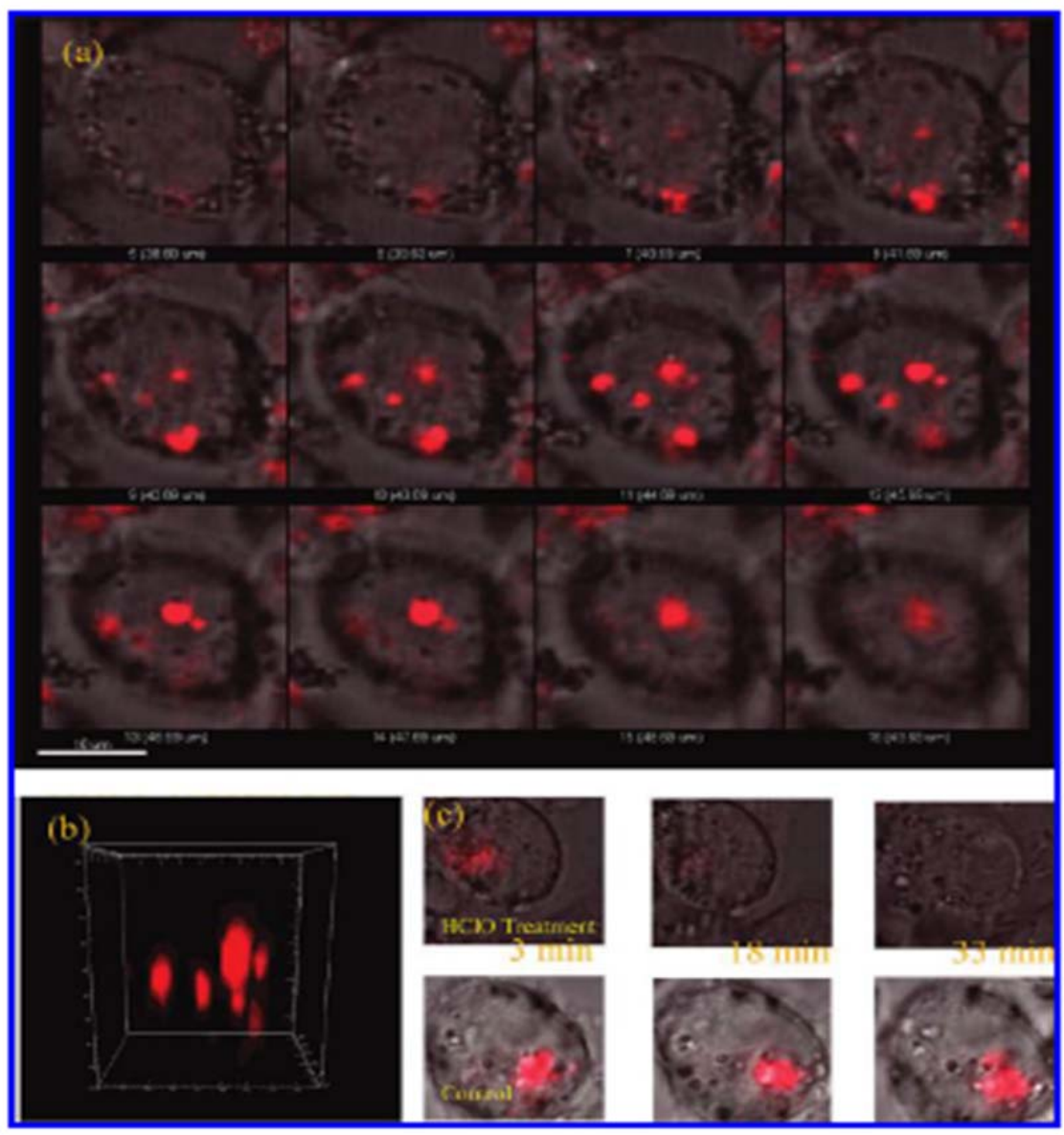

Fig. 4. (A) Z-stack gallery images of intracellular QDs-poly- $\mathrm{CO}_{2}$ - The intracellular localization of QDs-poly- $\mathrm{CO}_{2}^{-}$was confirmed by scanning optical sections along z direction (from bottom to top). The confocal $\mathrm{z}$ stacks were acquired with $1 \mu \mathrm{m}$ spacing, showing QDs-poly-CO2- distribution at various depths within the cell. (B) 3D image of intracellular QDs-poly- $\mathrm{CO}_{2}^{-}$in (A) was created by assembling the $\mathrm{z}$ stack images from successive focal planes with $1 \mu \mathrm{m}$ spacing. (C) Quenching effect of $\mathrm{HClO}$ on the intracellular QDs-poly- $\mathrm{CO}_{2}^{-}$(from right to left: 0,15 , and $30 \mathrm{~min}$ ). Reprinted with permission from Ref. [117]. Copyright (2010) American Chemical Society. 
the QDs probe to the leukocyte through phagocytosis. The selective screening of different endogenous ROS was first conducted on the bare QDs in cell-free medium which indicated that only $\mathrm{HOCl}$ induced a significant blue shift of the emission wavelength through oxidative etching of the QDs surface. Hence, the microbeads were conjugated to the QDs through amide bond formation for the cellular detection of $\mathrm{HOCl}$. Cellular quantification of intraphagosomal $\mathrm{HOCl}$ produced from single isolated neutrophils (activated with PMA) induced a blue-shift spectrum of the QDsdecorated microbeads, which was consistent with the result obtained in a cell-free medium. By measuring the variation in concentration of $\mathrm{HOCl}$ as a function of the number of $\mathrm{HOCl}$ molecules collected per microbead, the calibration curve of the probe was expressed as the magnitude of the spectral shift. Hence, the quantity of $\mathrm{HOCl}$ molecules was derived from the magnitude of the spectral shift. The concentration of $\mathrm{HOCl}$ thus quantified by this method was $6.5 \pm 0.9 \times 10^{8} \mathrm{HOCl}$ molecules. An inhibitory assay was carried out to verify that the spectral shift was due to the endogenous $\mathrm{HOCl}$ secreted from neutrophil. Two types of enzymes known to generate phagocytic $\mathrm{HOCl}$ were employed to stimulate the cells. It was found that a very minor and negligible spectral shift of the microbead-conjugated QDs was observed which thus served to confirm that the spectral blue-shift induced by the intraphagosomal generated $\mathrm{HOCl}$ on the phagocytosed microbeadconjugated QDs was indeed due to the presence of $\mathrm{HOCl}$. In addition, in vivo quantification of $\mathrm{HOCl}$ generated from hepatic leukocytes of rats elicited with lipopolysaccharide (LPS) was carried out using the proposed microbeads-conjugated QDs. The quantification of $\mathrm{HOCl}$ from the LPS-elicited rats was $5.9 \pm 0.8 \times 10^{8} \mathrm{HOCl}$ 
molecules. This excellent work was the first reported quantification of $\mathrm{HOCl}$ in cells and small animals. In a related report, it was also demonstrated that $\mathrm{HOCl}$ generated from HL60 cells quenched the fluorescence of QDs-poly- $\mathrm{CO}_{2}-$ [119].

\section{QDs fluorescent probes to detect RNS}

\subsection{Nitric oxide}

Nitric oxide is a short-lived gas which is generated endogenously and it plays a key role in cell signalling in the body. In 1987, Palmer et al. and Ignarro et al. simultaneously recognized $\mathrm{NO}$ as the relaxing factor derived in the endothelium $[120,121]$. Among the QDs-based fluorescent probes for ROS/RNS, NO is the most common and this may be due to its physiological and biological significance. For example, the modulation of different cancer-related effects has been reported to be induced by NO [122-126]. It can also act as an infector species in the human body to combat infection [74]. Hence, the need for suitable probes for its detection is of significant interest. A number of reports have shown that QDs have the potential to release ROS/RNS under photoactivation [127,128]. However, the ability of QD fluorescence probes to act both as a donor and sensor for RNS is a unique property which can serve to avoid potential error in experimental analysis. Tan et al. developed a CdTe QD-carboxymethyl chitosan (CMC) nanocomposite probe that can both release and detect NO in Porcine iliac artery endothelial (PIEC) cells. Results from fluorescence imaging showed that the probe was significantly quenched upon release of NO. [128]. As shown in Fig. 5, it was also demonstrated that the fluorescence of the CdTe QD-CMCS probe was quenched by increasing 



C

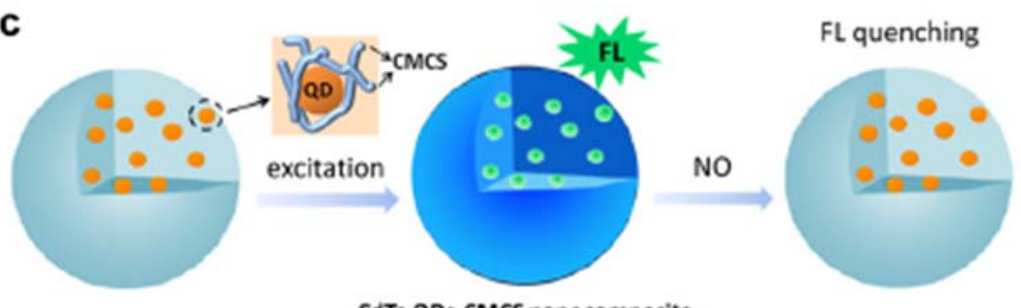

CdTe QDs-CMCS nanocomposite

Fig. 5. (a) UV-vis absorbance and (b) Fluorescence spectra of CdTe QD-CMCS in the presence of different amounts of NO. The arrow indicates increasing concentration. (Inset) Stern-Volmer quenching plot. (c) Schematic illustration of fluorescence effect and fluorescence quenching by NO of CdTe QD-CMCS. Reproduced from ref. [128]. Copyright (2012), with permission from Elsevier. 
concentration of NO in aqueous solution and resulted in a slight red shift of the maximum absorption wavelength of the QD probe. Fig. 5c was employed to describe the reaction mechanism which was due to the formation of a NO-Cd complex induced from the fluorescence quenching process. However, no useful information was provided to demonstrate that the probe was highly selective to NO without interference from other species. In a similar development, a CdTe QDs-poly(Nisopropylacrylamide (PNIPAM) hybrid nanogel diazeniumdiolates system capable of releasing and detecting NO was recently reported [129]. The presence of the nanogel was used to aid the reaction of NO which then reacted with the QDsPNIPAM nanocomposite to form the QDs-PNIPAM nanogel diazeniumdiolates. The ability of NO to diffuse to the QDs surface to form a NO-Cd complex was attributed to the mechanism of detection of NO. The selectivity of the probe for NO release in the presence of other ROS/RNS was conducted and the results showed that the presence of other ROS/RNS had a negligible effect on the fluorescence of the probe. Furthermore, the release and detection of $\mathrm{NO}$ was reflected in the fluorescence of the QDs-PNIPAM nanogel diazeniumdiolates probe which decreased progressively upon the release of NO.

In related studies, the fluorescence of CdSe QDs capped with triethanolamine was significantly quenched by the presence of varying concentrations of NO [130]. A two-way reaction mechanism was proposed for NO detection. The first involves direct quenching due to the formation of a NO-Cd complex which served to induce a defect state on the QDs surface and hence influence the fluorescence quenching. The second involved indirect quenching due to the consumption of dissolved oxygen. 
The proposed probe displayed good selectivity for NO. The fluorescence sensing of NO based on QDs adsorbed on a solid support has been reported [131]. CdSe/ZnS QDs which were adsorbed on polymethacrylate surfaces for fluorescence sensing of NO showed that the presence of NO significantly quenched the fluorescence of the probe in a sigmodial manner. However, the selectivity of the sensor towards NO was not studied and the mechanism of detection was unclear. A CdSe QDs-chitosan (CS) nanocomposite probe capable of detecting NO based on the ability of the later to quench the fluorescence of the probe is described in ref. [132]. The detection mechanism was attributed to a similar quenching process described above based on the formation of a NO-Cd complex. However, the selectivity of the sensor for NO was not reported. In other related development, a CdS QDs-polymethyl methacrylate (PMMA) nanocomposite sensor for NO based on the quenching sensitivity of $\mathrm{NO}$ to influence the fluorescence intensity of the probe has been reported [133]. A two detection mechanism was proposed based on either the degradation of the PMMA molecule by NO which then influenced the surface properties of the QDs or the formation of ionic complexes between NO and Cd ion on the QDs surface. However, as we have observed for most of the QDs fluorescence sensors reported above, the ability of the QDs-PMMA probe to selectively detect NO without interference from other related species was not studied. Recent reports employing CdSe QDs-chitosan nanocomposite [134] and CdSe QDs-hybrid nanospheres [135] for the fluorescence detection of NO based on quenching of the QDs probe has been reported. For the sensors developed in ref. [134] and [135], selectivity studies were carried out in the presence of other species with results 
indicating the probes were highly selective to NO, but the reaction mechanism was not explained in ref. [134] while the reaction mechanism described in ref. [135] was similar to the work reported in ref. [129].

Gel-based materials for the development of optical sensors have been shown to exhibit attractive properties due to their ability to trap photoactive molecules within the gel matrix and preserving the sensing properties [136]. A CdSe/ZnS QDsorganogel hybrid sensor for NO was reported by Wadhavane et al. in aqueous solution [137]. Varying concentrations of NO quenched the fluorescence of the QDsorganogel probe but no detail of selectivity studies was provided.

The design of fluorescent probes involving the attachment of specific molecules or compounds which have affinity for the analyte of interest is an efficient way of developing analyte-specific fluorescent probes. Hence, the ability of NO to "switch ON" the fluorescence of QDs-based probes has been reported by Wang at al. [138]. The grafting of tris(dithiocarbamato)iron III complex [Fe(DTCS) $\left.{ }_{3}\right]^{3-}$ (NO sensitive complex) on the surface of CdSe/ZnS QDs by ionic interaction was developed for the fluorescence "switch ON" sensing of NO. Upon ionic interaction of the QDs with $\left[\mathrm{Fe}(\mathrm{DTCS})_{3}\right]^{3-}$, the fluorescence of the QDs-[Fe(DTCS $\left.)_{3}\right]^{3-}$ probe was quenched and the presence of varying concentrations of $\mathrm{NO}$ restored the fluorescence in a concentration dependent manner. The detection mechanism was attributed to the ability of NO to inhibit the energy transfer process from the QDs to surface attached $\left[\mathrm{Fe}(\mathrm{DTCS})_{3}\right]^{3-}$ complex by acting both as a strong field ligand in its oxidized state and a one-electron reductant . The selectivity of the nanoprobe for NO in the presence of several other species was studied and results indicated suitable selectivity for NO. 


\subsection{Peroxynitrite anion}

Peroxynitrite is a reaction product of superoxide radical and nitric oxide radical. It is also a nitrating mediator that instigates oxidative and tissue molecular damage and it is a potent biological oxidant $[\mathbf{1 3 9 , 1 4 0 ]}$. It has been reported that in the presence of bicarbonate, $\mathrm{ONOO}^{-}$decays at a fast rate to $\bullet \mathrm{NO}_{2}$ and $\approx 33 \% \mathrm{CO}_{3} \bullet$ - The fast decay reaction has been attributed to the reaction of $\mathrm{ONOO}^{-}$with $\mathrm{CO}_{2}$ [141]. The problem with ONOO- is its instability in neutral physiological $\mathrm{pH}$ and upon protonation, it decays at a fast rate $\left(t_{1 / 2}<1 \mathrm{~s}\right)$ to its conjugate acid peroxynitrous acid $(\mathrm{ONOOH})$. It also isomerizes to nitrate by a first-order decay reaction. These complications make it extremely difficult to develop fluorescent probes that are specific for ONOO-. In addition, buffers such as Tris and 4-(2-hydroxyethyl)-1-piperazineethanesulfonic acid (HEPES) are not recommended for ONOO- detection due to interference with its detection. Hence, phosphate buffer solution is the recommended experimental medium for $\mathrm{ONOO}^{-}$detection. QDs fluorescent probes for ONOO- are extremely rare, in fact, the only probe reported to date involves a comparative study in which three types of QDs composed of MPA-CdTe, GSH-TGA-CdTe@ZnS and MPA-TGACdTe@ZnS QDs were screened for their sensitive and selective response to ONOOin phosphate buffer solution at $\mathrm{pH} 9.4$ [142]. It was demonstrated that the sensitivity of the probe towards ONOO- followed the order: MPA-TGA-CdTe@ZnS > GSH-TGACdTe@ZnS > MPA-CdTe QDs while the selectivity followed the order: GSH-TGACdTe@ZnS > MPA-TGA-CdTe@ZnS > MPA-CdTe QDs. The high selectivity for $\mathrm{ONOO}^{-}$was attributed to the steric effect induced by the bulky nature of the GSH 
ligand on the QDs surface which can inhibit oxidative attack from other interfering species. The mechanism of detection was attributed to the ability of the nitrating function of ONOO- to interact with the $\mathrm{Cd}^{2+}$-thiolate bond of the QDs surface. This implied that the stronger the bond the less sensitive the QDs to ONOO-

\section{Conclusions and future outlook}

When comparing the surge in development of fluorescent probes for ROS/RNS using organic dyes, it is clearly evident that the development of QD fluorescent probes for ROS/RNS is still a major challenge. This is summarily due to unfavourable properties of ROS/RNS coupled with difficulties in finding a proper mechanistic reaction match between the surface properties of the QDs probe and the target ROS/RNS. Of the general criteria listed in Section 2, point 1 was only justified for the quantification of $\mathrm{HOCl}$ in cellular environment while point 2 and point 3 have only been justified to same degree. While some groups have had major breakthroughs in in vivo detection of some ROS/RNS, the proof for specific detection of the ROS/RNS (point 4) is still a major challenge. It is important to note that the effectiveness of a probe needs to be demonstrated by its specificity towards a particular type of target species.

It is generally argued that to attribute a particular mechanistic reaction effect to a species, it is necessary to carry out more than one experimental assay. However, while this is often desirable, it yields no advantage if the assays exhibit similar mechanism, i.e. evidence for $\mathrm{HOCl}$ or $\mathrm{O}_{2} \bullet-$ is of no advantage if the assays involve systems that produce both these species. It is important that the assays need to 
behave differently, such as using a specifically designed fluorescent probe for the target species.

Generally, we suggest that special attention needs to be focused on developing QDs probes with surface functionality specific to a particular type of ROS/RNS. This will serve to eliminate false positive interpretation of experimental data, enhance specificity and provide clearer reaction mechanism information. Also, we advise that in order to conduct an effective selective study of the sensor, the fluorescence response of other analytes (which behave similarly to the target analytes and may be expected to be present in the sample solutions) should be evaluated under the same conditions used for the target analytes. This will ultimately justify the selectivity and specificity of the sensor. In addition, other factors which should be considered are the use of QDs with high fluorescence quantum yields and low toxicity. Near infrared QDs are also desirable for fluorescence imaging of ROS/RNS due to deeper cell penetration. We hope this review will assist readers/researchers by highlighting critical points needed in developing suitable novel QDs probes for ROS/RNS.

\section{Acknowledgement}

O. Adegoke thanks the University of Pretoria for a postdoctoral fellowship.

\section{References}

1) J.P. Kehrer, Free-radicals as mediators of tissue-injury and disease, Crit. Rev. Toxicol. 23 (1993) 21-48. 
2) B. Halliwell, J.M.C. Gutteridge, Reactive oxygen species: A radical role in development? Free Radical Biol. Med. Claredon Press, Oxford, 1989.

3) D. Liu, J. Liu, D. Sun, N.W. Alcock, J. Wen, Spinal cord injury increases iron levels: catalytic production of hydroxyl radical, Free Radical Biol. Med. 34 (2003) 64-71.

4) M. Valko, M. Izakovic, M. Mazur, C.J. Rhodes, J. Telser, Role of oxygen radicals in DNA damage and cancer incidence, Mol. Cell. Biochem. 266 (2004) 37-56.

5) C. Nathan, Specificity of a third kind: reactive oxygen and nitrogen intermediates in cell signalling, J. Clin. Invest. 111 (2003) 769-778.

6) N.B. Ames, M.K. Shigenaga, T.M. Hagen, Oxidants, antioxidants, and the degenerative disease of aging, Proc. Natl. Acad. Sci. USA 90 (1993) 7915-7922.

7) B. Halliwell, J.M.C. Gutteridge, C.E. Cross, Free-radicals, antioxidants, and human-disease -Where are we now, J. Lab. Clin. Med. 119 (1992) 598-620.

8) P. F. Bove, A. van der Vliet, Nitric oxide and reactive nitrogen species in airway epithelial signaling and inflammation, Free Radical Biol. Med. 41 (2006) 515-527.

9) M.P. Fink, Role of reactive oxygen species in acute respiratory distress syndrome, Curr. Opin. Crit. Care 8 (2002) 6-11.

10) D. Hernández-García, C.D. Wood, S. Castro-Obregón, L. Covarrubias, Reactive oxygen species: A radical role in development?, Free Radical Biol. Med. 49 (2010) 130-143.

11) A. Gomes, E. Fernandes, José L.F.C. Lima, Use of Fluorescence Probes for Detection of Reactive Nitrogen Species: A Review, J. Fluoresc. 16 (2006) 119-139. 
12) F-J. Schmitt, G. Renger, T. Friedrich, V.D. Kreslavski, S.K. Zharmukhamedov, D.A. Los, V.V. Kuznetsov, S.I. Allakhverdiev, Reactive oxygen species: Reevaluation of generation, monitoring and role in stress-signaling in phototrophic organisms, Biochim. Biophys. Acta 1837 (2014) 835-848.

13) M. Dizdaroglu, Chemical determination of free radical-induced damage to DNA, Free Radical Biol. Med. 10 (1991) 225-242.

14) C.C. Winterbourn, The challenges of using fluorescent probes to detect and quantify specific reactive oxygen species in living cells, Biochim. Biophys. Acta 1840 (2014) 730-738.

15) L.I. Leichert, F. Gehrke, H.V. Gudiseva, T. Blackwell, M. Ilbert, A.K. Walker, J.R. Strahler, P.C. Andrews, U. Jakob, Quantifying changes in the thiol redox proteome upon oxidative stress in vivo, Proc. Natl. Acad. Sci. USA. 105 (2008) 8197-8202.

16) E. Niki, Biomarkers of lipid peroxidation in clinical material, Biochim. Biophys. Acta 1840 (2014) 809-817.

17) J. Cadet, T. Douki, D. Gasparutto, J.L. Ravanat, Oxidative damage to DNA: formation, measurement and biochemical features, Mutat. Res. 531 (2003) 5-23.

18) P.J. Thornalley, N. Rabbani, Detection of oxidized and glycated proteins in clinical samples using mass spectrometry - a user's perspective, Biochim. Biophys. Acta 1840 (2014) 818-829.

19) J. Zielonka, M. Zielonka, A. Sikora, J. Adamus, J. Joseph, M. Hardy, O. Ouari, B.P. Dranka, B. Kalyanaraman, Global profiling of reactive oxygen and nitrogen 
species in biological systems: high-throughput real-time analyses, J. Biol. Chem. 287 (2012) 2984-2995.

20) C.C.Winterbourn, A.J. Kettle, Biomarkers of myeloperoxidase-derived hypochlorous acid, Free Radic. Biol. Med. 29 (2000) 403-409.

21) M.B. Feeney, C. Schoneich, Proteomic approaches to analyze protein tyrosine nitration, Antiox. Redox Sign. (2013), PMID 23157221.

22) A.J Kettle, A.M. Albrett, A.L. Chapman, N. Dickerhof, L.V. Forbes, I. Khalilova, R. Turner, Measuring chlorine bleach in biology and medicine, Biochim. Biophys. Acta 1840 (2014) 781-793.

23) R. Radi, Nitric oxide, oxidants, and protein tyrosine nitration, Proc. Natl. Acad. Sci. USA. 101 (2004) 4003-4008.

24) M. Schäferling, D.B.M. Grögel, S. Schreml, Luminescent probes for detection and imaging of hydrogen peroxideMicrochim. Acta 174 (2010) 1-8.

25) P. Wardman, Fluorescent and luminescent probes for measurement of oxidative and nitrosative species in cells and tissues: progress, pitfalls, and prospects, Free Radical Biol. Med. 43 (2007) 995-1022.

26) M.M. Tarpey, D.A. Wink, M.B. Grisham, Methods for detection of reactive metabolites of oxygen and nitrogen: in vitro and in vivo considerations, Am. J. Physiol. 286 (2004) R431-R444.

27) S.I. Dikalov, D.G. Harrison, Methods for detection of mitochondrial and cellular reactive oxygen species, Antiox. Redox Sign. (2012), PMID 22978713 (epubl). 
28) G.J. Maghzal, K.H. Krause, R. Stocker, V. Jaquet, Detection of reactive oxygen species derived from the family of NOX NADPH oxidases, Free Radical Biol. Med. 53 (2012) 1903-1918.

29) B. Kalyanaraman, V. Darley-Usmar, K.J. Davies, P.A. Dennery, H.J. Forman, M.B. Grisham, G.E. Mann, K. Moore, L.J. Roberts 2nd, H. Ischiropoulos, Measuring reactive oxygen and nitrogen species with fluorescent probes: challenges and limitations, Free Radic. Biol. Med. 52 (2012) 1-6.

30) A. P. Alivisatos, Semiconductor Clusters, Nanocrystals, and Quantum Dots, Science 271 (1996) 933-937.

31) C. B. Murray, D. J. Norris and M. G. Bawendi, Synthesis and characterization of nearly monodisperse $\mathrm{CdE}(\mathrm{E}=$ sulfur, selenium, tellurium) semiconductor nanocrystallites, J. Am. Chem. Soc. 115 (1993) 8706-8715.

32) M. Bruchez, M. Moronne, P. Gin, S. Weiss, A. P. Alivisatos, Semiconductor Nanocrystals as Fluorescent Biological Labels, Science 281 (1998) 2013-2016.

33) Z. A. Peng, X. Peng, Formation of high-quality CdTe, CdSe, and CdS nanocrystals using CdO as precursor, J. Am. Chem. Soc. 123 (2001) 183-184.

34) N. Gaponik, D. V. Talapin, A. L. Rogach, K. Hoppe, E. V. Shevchenko, A. Kornowski, A. Eychm"uller and H. Weller, Thiol-Capping of CdTe Nanocrystals: An Alternative to Organometallic Synthetic Routes, J. Phys. Chem. B 106 (2002) $7177-7185$.

35) W. C.W. Chan, S. M. Nie, Science 281 (1998) Quantum Dot Bioconjugates for Ultrasensitive Nonisotopic Detection2016-2018. 
36) S. V. Gaponenko, Optical properties of semiconductor nanocrystals, Cambridge university press, Cambridge, 1998.

37) R. Gill, M. Zayats, I. Willner, Semiconductor Quantum Dots for Bioanalysis, Angew. Chem. Int. Ed 47 (2008) 7602-7625.

38) P. Reiss, M. Protiére, L. Li, Core/Shell Semiconductor Nanocrystals, Small 5 (2009) 154-168.

39) S. L. Hempel, G. R. Buettner, Y. Q. O'Malley, D. A. Wessels and D. M. Flaherty, Dihydrofluorescein diacetate is superior for detecting intracellular oxidants: comparison with 2',7'-dichlorodihydrofluorescein diacetate, 5(and 6)-carboxy$2^{\prime}, 7^{\prime}$-dichlorodihydrofluorescein diacetate, and dihydrorhodamine 123, Free Radical Biol. Med. 27 (1999) 146-159.

40) G. Kim, Y.-E. K. Lee, H. Xu, M. A. Philbert, R. Kopelman, Nano-encapsulation Method for High Selectivity Sensing of Hydrogen Peroxide inside Live Cells, Anal. Chem. 82 (2010) 2165-2169.

41) L.-C. Lo, C.-Y. Chu, Development of highly selective and sensitive probes for hydrogen peroxide, Chem. Commun. (2003) 2728-2729.

42) M. C. Y. Chang, A. Pralle, E. Y. Isacoff and C. J. Chang, A Selective, CellPermeable Optical Probe for Hydrogen Peroxide in Living Cells, J. Am. Chem. Soc. 126 (2004) 15392-15393.

43) S. Pou, Y.-I. Huang, A. Bhan, V. S. Bhadti, R. S. Hosmane, S. Y. Wu, G.-L. Cao, G. M. Rosen, A fluorophore-containing nitroxide as a probe to detect superoxide and hydroxyl radical generated by stimulated neutrofils, Anal. Biochem. 212 (1993) 85-90. 
44) X.-F. Yang, X.-Q. Guo, Study of nitroxide-linked naphthalene as a fluorescence probe for hydroxyl radicals, Anal. Chim. Acta, 434 (2001) 169-177.

45) X.-F. Yang, X.-Q. Guo, Investigation of the anthracene-nitroxide hybrid molecule as a probe for hydroxyl radicals, Analyst 126 (2001) 1800-1804.

46) P. Li, T. Xie, X. Duan, F. Yu, X. Wang, B.Tang, A New Highly Selective and Sensitive Assay for Fluorescence Imaging of $\mathrm{OH}$ in Living Cells: Effectively Avoiding the Interference of Peroxynitrite, Chem. Eur. J. 16 (2010) 1834-1840.

47) J. J. Gao, K. H. Xu, B. Tang, L. L. Yin, G. W. Yang, L. G. An, Selective detection of superoxide anion radicals generated from macrophages by using a novel fluorescent probe, FEBS J. 274 (2007) 1725-1733.

48) N. Medvedeva, V. V. Martin, A. L. Weis, G. I. Likhtenshten, Dual fluorophorenitronyl probe for investigation of superoxide dynamics and antioxidant status of biological systems, J. Photochem. Photobiol. A 163 (2004) 45-51.

49) R. O. Olojo, R. H. Xia, J. J. Abramson, Spectrophotometric and fluorometric assay for superoxide ion using 4-Chloro-7-nitrobenzo-2-oxa-1,3-diazole, Anal. Biochem. 339 (2005) 338-344.

50) B. Tang, L. Zhang, J.-X. Hu, P. Li, H. Zhang, Y.-X. Zhao, Indirect determination of superoxide anion radical in the plant of red sage based on vanillin-8aminoquinoline with fluorescence, Anal. Chim. Acta 502 (2004) 125-131.

51) H. Maeda, K. Yamamoto, Y. Nomura, I. Kohno, L. Hafsi, N. Ueda, S. Yoshida, M. Fukuda, Y. Fukuyasu, Y. Yamauchi, N. Itoh, Probes for Superoxide. Based on. Based on Nonredox Mechanism. Mechanism, J. Am. Chem. Soc. 127 (2005) 68-69. 
52) M. M. Tarpey, D.A. Wink, M. B.Grisham, Methods for detection of reactive metabolites of oxygen and nitrogen: In vitro and in vivo considerations, Am. J. Physiol. Regul. Integr. Comp. Physiol. 286 (2004) R431-R444.

53) T. P. Misko, R. J. Schilling, D. Salvemini,W. M. Moore, M. G. Currie, A fluorometric assay for the measurement of nitrite in biological samples, Anal. Biochem. 214 (1993) 11-16.

54) N. Nakatsubo, H. Kojima, K. Sakurai, K. Kikuchi, H. Nagoshi, Y. Hirata, T. Akaike, H. Maeda, Y. Urano, T. Higuchi, T. Nagano, Improved nitric oxide detection using 2,3- diaminonaphthalene and its application to the evaluation of novel nitric oxide synthase inhibitors, Biol. Pharm. Bull. 21 (1998) 1247- 1250.

55) L. Gonzalez-Santiago, S. Lopez-Ongil, M. Rodriguez-Puyol, D. Rodriguez-Puyol, Decreased nitric oxide synthesis in human endothelial cells cultured on type I collagen, Circ. Res. 90 (2002) 539-545.

56) N. W. Kooy, J. A. Royall, H. Ischiropoulos, J. S. Beckman, Peroxynitrite-mediated oxidation of dihydrorhodamine 123, Free Radic. Biol. Med. 16 (1994) 149-156.

57) P. G. Gunasekar, A. G. Kanthasamy, J. L. Borowitz, G. E. Isom, Monitoring intracellular nitric oxide formation by dichlorofluorescin in neuronal cells, J. Neurosci. Methods 61 (1995) 15- 21.

58) S.J. Rosenthal, J. McBride, S.J. Pennycock, L.C. Feldman, Synthesis, surface studies, composition and structural characterization of CdSe, core/shell and biologically active nanocrystals, Surf. Sci. Rep. 62 (2007) 111-157.

59) R. Freeman, I. Willner, Optical molecular sensing with semiconductor quantum dots (QDs), Chem. Soc. Rev. 41 (2012) 4067-4085. 
60) W.A. Hild, M. Breunig, A. Goepferich, Quantum dots - Nano-sized probes for the exploration of cellular and intracellular targeting, Eur. J. Pharm. Biopharm. 68 (2008) 153-168.

61) H.M.E. Azzazy, M.M.H. Mansour, S.C. Kazmierczak, From diagnostics to therapy: Prospects of quantum dots, Clin. Biochem. 40 (2007) 917-927.

62) C. Frigerio, D.S.M. Ribeiro, S.S.M. Rodrigues, V.L.R.G. Abreu, J.A.C. Barboza, J.A.V. Prior, K.L. Marques, J.L.M. Santos, Application of quantum dots as analytical tools in automated chemical analysis:A review, Anal. Chim. Acta 735 (2012) 9-22.

63) W.R. Algar, A.J. Tavares, U.J. Krull, Beyond labels: A review of the application of quantum dots as integrated components of assays, bioprobes, and biosensors utilizing optical transduction, Anal. Chim. Acta 673 (2010) 1-25.

64) H. Mattoussi, G. Palui, H.B. Na, Luminescent quantum dots as platforms for probing in vitro and in vivo biological processes, Adv. Drug Deliver. Rev. 64 (2012) 138-166.

65) T. Jamieson, R. Bakhshi, D. Patrova, R. Pocock, M. Imani, A.M. Seifalian, Biological applications of quantum dots, Biomaterials 28 (2007) 4717-4732.

66) Y. Zhang, T-H. Wang, Quantum Dot Enabled Molecular Sensing and Diagnostics, Theranostics 2 (2012) 631-654.

67) J.B. Delehanty, K. Susumu, R.L. Manthe, W.R. Algar, I.L. Medintz, Active cellular sensing with quantum dots: Transitioning from research tool to reality; a review, Anal. Chim. Acta 750 (2012) 63-81. 
68) J.R. Lakowicz, Principles of Fluorescence Spectroscopy, 2nd ed.; Kluwer Academic Press: New York, 1999.

69) K.P. Carter, A.M. Young, A.E. Palmer, Fluorescent Sensors for Measuring Metal Ions in Living Systems, Chem. Rev. 114 (2014) 4564-4601.

70) B.F. Godley, F.A. Shamsi, F.Q. Liang, S.G. Jarrett, S. Davies, M. Boulton, Blue light induces mitochondrial DNA damage and free radical production in epithelial cells, J. Biol. Chem. 280 (2005) 21061-21066.

71) S. G. Rhee, Cell signaling. H2O2, a necessary evil for cell signalling, Science 312 (2006) 1882-1883.

72) T. Finkel, Oxidant signals and oxidative stress, Curr. Opin. Cell Biol. 15 (2003) 247-254.

73) J. R. Stone, S. Yang, Hydrogen peroxide: a signaling messenger, Antioxid. Redox Signaling 8 (2006) 243-270.

74) X. Chen, X. Tian, I. Shin, J. Yoon, Fluorescent and luminescent probes for detection of reactive oxygen and nitrogen species, Chem. Soc. Rev. 40 (2011) 4783-4804.

75) A. Lobnik, M. Cajlakovic, Sol-gel based optical sensor for continuous determination of dissolved hydrogen peroxide, Sens. Actuators B 74 (2001) 194199.

76) P. Trinder, Determination of glucose in blood using glucose oxidase with an alternative oxygen acceptor, Ann. Clin. Biochem. 6 (1969) 24-27.

77) H. Gallati, Aktivitätsbestimmung von Peroxidase mit Hilfe des Trinder-Reagenz J. Clin. Chem. Clin. Biochem. 15 (1977) 699-793. 
78) M. Mizoguchi, M. Ishiyama, M. Shiga, Water-soluble chromogenic reagent for colorimetric detection of hydrogen peroxide-an alternative to 4-aminoantipyrine working at a long wavelength, Anal. Commun. 35 (1998) 71-74.

79) M. Mascini, D. Moscone, Amperometric acetylcholine and choline sensors with immobilized enzymes, Anal. Chim. Acta179 (1986) 439-444.

80) G.J. Moody, G.S. Sanghera, J.D.R. Thomas, Modified platinum wire glucose oxidase amperometric electrode, Analyst 111 (1986) 1235-1238.

81) J. Wang, Electrochemical glucose biosensors, Chem. Rev. 108 (2008) 814-825.

82) E.W. Miller, C.J. Chang, Fluorescent probes for nitric oxide and hydrogen peroxide in cell signalling, Curr. Opin. Chem. Biol. 11 (2007) 620-625.

83) W. Zhao, Lighting up H2O2: the molecule that is a "necessary evil" in the cell, Angew Chem. Int. Ed. 48 (2009) 3022-3024.

84) M.C.Y. Chang, A. Pralle, E.Y. Isacoff, C.J. Chang, A selective, cell-permeable optical probe for hydrogen peroxide in living cells, J. Am. Chem. Soc. 126 (2004) 15392-15393.

85) E.W. Miller, A.E. Albers, A. Pralle, E.Y. Isacoff, C.J. Chang, Boronate-based fluorescent probes for imaging cellular hydrogen peroxide, J. Am. Chem. Soc. 127 (2005) 16652-16659.

86) M. Hu, J. Tian, H-T. Lu, L-X. Weng, L-H. Wang, $\mathrm{H}_{2} \mathrm{O}_{2}$-sensitive quantum dots for the label-free detection of glucose, Talanta 82 (2010) 997-1002.

87) Z. Chen, X. Ren, X. Meng, D. Chen, C. Yan, J. Ren, Y. Yuan, F. Tang, Optical detection of choline and acetylcholine based on $\mathrm{H} 2 \mathrm{O} 2$-sensitive quantum dots, Biosens. Bioelectron. 28 (2011) 50-55. 
88) S. Liu, J. Hu, H. Zhang, X. Su, CuInS 2 quantum dots-based fluorescence turn off/on probe for detection of melamine, Talanta 101 (2012) 368-373.

89) L. Yang, X. Ren, X. Mang, H. Li, F. Tang, Optical analysis of lactate dehydrogenase and glucose by CdTe quantum dots and their dual simultaneous detection, Biosens. Bioelectron. 26 (2011) 3488-3493.

90) Y. Li, B. Li, J. Zhang, $\mathrm{H}_{2} \mathrm{O}_{2}$ - and pH-sensitive CdTe quantum dots as fluorescence probes for the detection of glucose, Luminescence 28 (2013) 667-672.

91) M.C. Mancini, B.A. Kairdolf, A.M. Smith, S. Nie, Oxidative Quenching and Degradation of Polymer-Encapsulated Quantum Dots: New Insights into the Long-Term Fate and Toxicity of Nanocrystals in Vivo, J. Am. Chem. Soc. 130 (2008) 10836-10837.

92) A.J. Kettle, A.C. Carr, C.C. Winterbourn, Assays using horseradish peroxidase and phenolic substrates require superoxide dismutase for accurate determination of hydrogen peroxide production by neutrophils, Free Radic. Biol. Med. 17 (1994) 161-164.

93) J. Yuan, W. Guo, E. Wang, Utilizing a CdTe Quantum Dots-Enzyme Hybrid System for the Determination of Both Phenolic Compounds and Hydrogen Peroxide, Anal. Chem. 80 (2008) 1141-1145.

94) J.G. Zhao, R.W. Henkens, J. Stonehuerner, J.P.O. Daly, A.L. Crumbliss, Direct electron transfer at horseradish peroxidase-colloidal gold modified electrodes, J. Electroanal. Chem. 327 (1992) 109-119. 
95) X. Huang, J. Wang, H. Liu, T. Lan, J. Ren, Quantum dot-based FRET for sensitive determination of hydrogen peroxide and glucose using tyramide reaction, Talanta 106 (2013) 79-84.

96) O. Adegoke, S. Khene, T. Nyokong, Fluorescence "Switch on" of Conjugates of CdTe@ZnS Quantum Dots with Al, Ni and Zn Tetraamino-Phthalocyanines by Hydrogen Peroxide: Characterization and Applications as Luminescent Nanosensors, J. Fluoresc. 23 (2013) 963-974.

97) S.S.M. Rodrigues, D.S.M. Ribeiro, L. Molina-Garcia, A.R. Medina, J.A.V. Prior, J.L.M. Santos, Fluorescence enhancement of CdTe MPA-capped quantum dots by glutathione for hydrogen peroxide determination, Talanta 122 (2014) 157-165.

98) P. Wardman, Fluorescent and luminescent probes for measurement of oxidative and nitrosative species in cells and tissues: progress, pitfalls, and prospects, Free Radic. Biol. Med. 43 (2007) 995-1022.

99) J.A. Imlay, Pathways of oxidative damage, Annu. Rev. Microbiol. 57 (2003) 395418.

100) A.S. Tan, M.V. Berridge, Superoxide produced by activated neutrophils efficiently reduces the tetrazolium salt, WST-1 to produce a soluble formazan: a simple colorimetric assay for measuring respiratory burst activation and for screening anti-inflammatory agents, J. Immunol. Methods 238 (2000) 59-68.

101) D-W. Li, L-X. Qin, Y. Li, R.P. Nia, Y-T. Long, H-Y. Chen, CdSe/ZnS quantum dot-Cytochrome c bioconjugates for selective intracellular $\mathrm{O}_{2}$ sensing, Chem. Commun. 47 (2011) 8539-8541. 
102) M. Cao, C. Cao, M. Liu, P. Wang, C. Zhu, Selective fluorometry of cytochrome c using glutathione-capped CdTe quantum dots in weakly basic medium, Michrochim. Acta 165 (2009) 341-346.

103) L-W. Qin, W. Ma, D-W. Li, Y. Li, X. Chen, H-B. Kraatz, T.D. James, Y-T. Long, Coenzyme Q Functionalized CdTe/ZnS Quantum Dots for Reactive Oxygen Species (ROS) Imaging, Chem. Eur. J. 17 (2011) 5262-5271.

104) O. Adegoke, E. Antunes, T. Nyokong, Nanoconjugates of CdTe@ZnS quantum dots with cobalt tetraamino-phthalocyanine: Characterization and implications for the fluorescence recognition of superoxide anion, J. Photochem. Photobio. A: Chem. 257 (2013) 11-19.

105) O. Adegoke, T. Nyokong, Effects of analytes on the fluorescence properties of CdTe@ZnS quantum dots decorated with cobalt tetraamino-phthalocyanine, J. Lumin. 146 (2014) 275-283.

106) C. Nathan, Specificity of a third kind: reactive oxygen and nitrogen intermediates in cell signalling, J. Clin. Invest. 111 (2003) 769-778.

107) P.E. Morgan, .I. Pattison M.J. Davies, Quantification of hydroxyl radicalderived oxidation products in peptides containing glycine, alanine, valine, and proline, Free Radic. Biol. Med. 52 (2012) 328-339.

108) B. Halliwell, J.M.C. Gutteridge, Biologically relevant metal ion-dependent hydroxyl radical generation An update, FEBS Lett. 307 (1992) 108-112.

109) B. Halliwell, J.M.C. Gutteridge, Oxygen free radicals and iron in relation to biology and medicine: some problems and concepts, Arch. Biochem. Biophys. 246 (1986) 501-514. 
110) S.-X. Chen, P. Schopfer, Hydroxyl-radical production in physiological reactions. A novel function of peroxidise, Eur. J. Biochem. 260 (1999) 726-735.

111) B. Bektaşoğlu, M. Ŏzyürek, K. Güçlü, R. Apak, Hydroxyl radical detection with a salicylate probe using modified CUPRAC spectrophotometry and HPLC, Talanta 77 (2008) 90-97.

112) P. Wu, Y. Li, X-P. Yan, CdTe Quantum Dots (QDs) Based Kinetic Discrimination of $\mathrm{Fe}^{2+}$ and $\mathrm{Fe}^{3+}$, and CdTe QDs-Fenton Hybrid System for Sensitive Photoluminescent Detection of $\mathrm{Fe}^{2+}$, Anal. Chem. 81 (2009) 6252-6257.

113) O. Adegoke, T. Nyokong, A Comparative Study on the Sensitive Detection of Hydroxyl Radical Using Thiol-capped CdTe and CdTe/ZnS Quantum Dots, J. Fluoresc. 22 (2012) 1513-1519.

114) M.J. Davies, C.L. Hawkins, D.I. Pattison, M.D. Rees, Mammalian heme peroxidases: from molecular mechanisms to health implications, Antioxid. Redox Signal. 10 (2008) 1199-1234.

115) C.C. Winterbourn, Biological reactivity and biomarkers of the neutrophil oxidant, hypochlorous acid, Toxicology 181-182 (2002) 223-227.

116) C.C. Winterbourn, Reconciling the chemistry and biology of reactive oxygen species, Nat. Chem. Biol. 4 (2008) 278-286.

117) Y. Yan, S. Wang, Z. Liu, H. Wang, D. Huang, CdSe-ZnS Quantum Dots for Selective and Sensitive Detection and Quantification of Hypochlorite, Anal. Chem. 82 (2010) 9775-9781. 
118) Y-C. Yang, H-H. Lu, W-T. Wang, I. Liau, Selective and Absolute Quantification of Endogenous Hypochlorous Acid with Quantum-Dot Conjugated Microbeads, Anal. Chem. 83 (2011) 8267-8272.

119) Z. Liu, Y. Yan, S. Wang, W-Y. Ong, C.N. Ong, D. Huang, Assaying Myeloperoxidase Inhibitors and Hypochlorous Acid Scavengers in HL60 Cell Line Using Quantum Dots, Am. J. Biomed. Sci. 2 (2013) 140-153.

120) L.J. Ignarro, G.M. Buga, K.S. Wood, R.E. Byrns, G. Chaudhuri, Endotheliumderived relaxing factor produced and released from artery and vein is nitric oxide, Proc. Natl. Acad. Sci. USA 84 (1987) 9265-9269.

121) R.M.J. Palmer, A.G. Ferrige, S. Moncada, Nitric oxide release accounts for the biological activity of endothelial-derived relaxing factor, Nature 327 (1987) 524526.

122) L.L. Thomson, F.G. Lawton, R.G. Knowles, J.E. Basley, V. Riversomoreno, S. Moncada, NO synthase activity in human gynecological cancer, Cancer Res. 54 (1994) 1352-1354.

123) S. Taysi, C. Uslu, F. Akcay, M.Y. Sutbeyaz, MDA and nitric oxide in the plasma of patients with advanced laryngeal cancer, Surg. Today 9 (2003) 651-654. 124) C.S. Cabs, J.E. Brenman, K.D. Aldape, D.S. Bredt, M.A. Isrnael, Expression of NOS in human central nervous system tumors, Cancer Res. 55 (1995) 727-730.

125) S. Reveneau, L. Arnould, G. Jolimoy, S. Hilpert, P. Lejeune, V. Saint-Giorgio, C. Belichard, J.F. Jeannin, Nitric oxide synthase in human breast cancer is associated with tumor grade, proliferation rate, and expression of progesterone receptor, Lab. Invest. 79 (1999) 1215-1225. 
126) J. Prazma, P. Pertrusz, W. Mims, S.S. Ball, M.C. Weissler, Immunohistochemical characterization of NOS activity in squamous cell carcinoma of head and neck, Otolaryngol Head Neck Surg. 113 (1995) 541-549.

127) F-A. Kauffer, C. Merlin, L. Balan, R. Schneider, Incidence of the core composition on the stability, the ROS production and the toxicity of CdSe quantum dots, J. Hazard. Mater. 268 (2014) 246-255.

128) L. Tan, A. Wan, H. Li, Q. Lu, Novel quantum dots-carboxymethyl chitosan nanocomposite nitric oxide donors capable of detecting release of nitric oxide in situ, Acta Biomater. 8 (2012) 3744-3752.

129) L. Tan, A. Wan, H. Li, Quantum dots-poly(N-isopropylacrylamide) hybrid nanogel diazeniumdiolates as donors and real-time probes of nitric oxide, Mater. Chem. Phys. 138 (2013) 956-962.

130) X.Q. Yan, Z.B. Shang, Z. Zhang, Y. Wang, W.J. Jin, Fluorescence sensing of nitric oxide in aqueous solution by triethanolamine-modified CdSe quantum dots, Luminescence 24 (2009) 255-259.

131) V. Fabregat, M.A. Izquierdo, M.I. Burguete, F. Galindo, S.V. Luis, Quantum dot-polymethacrylate composites for the analysis of NOx by fluorescence spectroscopy, Inorg. Chim. Acta 381 (2012) 212-217.

132) L. Tan, A. Wan, H. Li, H. Zhang, Q. Lu, Biocompatible quantum dotsechitosan nanocomposites for fluorescence detection of nitric oxide, Mater. Chem. Phys. 134 (2012) 562-566. 
133) L. Ding T. Li, Y. Zhong, C. Fan, J. Huang, Synthesis and characterization of a novel nitric oxide fluorescent probe CdS-PMMA nanocomposite via in-situ bulk polymerization, Mat. Sci. Engr. C 35 (2014) 29-35.

134) E.F.C. Simões, J.M.M. Leităo, J.C.G. Esteves da Silva, NO Fluorescence Quantification by Chitosan CdSe Quantum Dots Nanocomposites, J. Fluoresc. 24 (2014) 639-648.

135) S. Liu, L. Jin, I.S. Chronakis, X. Li, M. Ge, Hyperbranched polyether hybrid nanospheres with CdSe quantum dots incorporated for selective detection of nitric oxide, Mater. Lett. 123 (2014) 104-106.

136) I. Yoshimura, Y. Miyahara, N. Kasagi, H. Yamane, A. Ojida and I. Hamachi, Molecular Recognition in a Supramolecular Hydrogel to Afford a Semi-Wet Sensor Chip, J. Am. Chem. Soc. 126 (2004) 12204-12205.

137) P.D. Wadhavane, M.A. Izquierdo, F. Galindo, M.I. Burguete, S.V. Luis, Organogel-quantum dots hybrid materials displaying fluorescence sensitivity and structural stability towards nitric oxide, Soft Matter 8 (2012) 4373-4381.

138) S. Wang, M-Y. Han, D. Huang, Nitric Oxide Switches on the Photoluminescence of Molecularly Engineered Quantum Dots, J. Am. Chem. Soc. 131 (2009) 11692-11694.

139) A. Priyam, S.C. Bhattacharya, A. Saha, Volatile interface of biological oxidant and luminescent CdTe quantum dots: implications in nanodiagnostics, Phys. Chem. Chem. Phys. 11 (2009) 520-529. 
140) L.B. Valdez, S. A' lvarez, T.Zaobornyj, A. Boveris, Polyphenols and red wine as antioxidants against peroxynitrite and other oxidants, Biol. Res. 37 (2004) 279286.

141) S. Goldstein, G. Czapski, Reactivity of peroxynitrite versus simultaneous generation of $\bullet \mathrm{NO}$ and $\mathrm{O}_{2} \bullet-$ toward NADH, Chem. Res. Toxicol. 13 (2000) 736741.

142) O. Adegoke, T. Nyokong, Probing the sensitive and selective luminescent detection of peroxynitrite using thiol-capped CdTe and CdTe@ZnS quantum dots, J. Lumin. 134 (2013) 448-455. 